\title{
Tailoring Iron Oxide Nanostructures for High-Capacity Lithium Storage
}

\author{
Yao Yao, Jiantao Li, Qinyou An, Liqiang Mai, ${ }^{*}$ and Liang Zhou* \\ State Key Laboratory of Advanced Technology for Materials Synthesis and Processing, International School of Materials \\ Science and Engineering, Wuhan University of Technology, Wuhan, Hubei 430070, China
}

\begin{abstract}
Iron oxides, such as hematite $\left(\alpha-\mathrm{Fe}_{2} \mathrm{O}_{3}\right)$, maghemite $\left(\gamma-\mathrm{Fe}_{2} \mathrm{O}_{3}\right)$, and magnetite $\left(\mathrm{Fe}_{3} \mathrm{O}_{4}\right)$, have been considered as alternative anode materials for lithium-ion batteries (LIBs) due to their high theoretical capacity, abundant reserves, low cost, and non-toxicity. However, their practical application has been hampered by the large volume expansion, which leads to rapid capacity fading. Nanostructure engineering has been demonstrated to be an effective avenue in tackling the volume variation issue and boosting the electrochemical performances. Herein, recent advances on nanostructure engineering of iron oxides for lithium storage are summarized. These nanostructures include 0D nanoparticles, 1D nanowires/nanorods/ nanofibers/nanotubes, 2D nanoflakes/nanosheets, as well as 3D porous/hollow/hierarchical architectures. The structureelectrochemical performance correlations are also discussed. It is believed that the performance optimization strategies summarized here might be extended to other high-capacity LIB anode materials.
\end{abstract}

Keywords iron oxide, nanostructure, nanocomposite, lithium storage, anode

\section{Introduction}

The global concerns of energy shortage and environmental pollution make the clean and sustainable energy an urgent need. ${ }^{[1-3]}$ With high energy density and long lifespan, rechargeable lithium-ion batteries (LIBs) are one of the most promising energy storage devices for portable electronics and electric vehicles. However, the current state-of-the-art LIBs can't meet the ever increasing demands on energy density. The current commercialized graphite-based anode suffers from low specific capacity $\left(372 \mathrm{mAh} \cdot \mathrm{g}^{-1}\right)$ and poor safety. Therefore, exploring alternative anode materials with high capacity and good safety has attracted growing attention. ${ }^{[4-16]}$

Transition metal oxides (TMOs) represent a promising family of high-capacity anode materials for LIBs. ${ }^{[17]}$ Based on a conversion reaction mechanism, they are able to provide a specific capacity of $700-1000 \mathrm{mAh} \cdot \mathrm{g}^{-1}$, which is two to three times to that of graphite. Among the various TMOs, iron oxides, such as hematite $\left(\alpha-\mathrm{Fe}_{2} \mathrm{O}_{3}\right)$, maghemite $\left(\gamma-\mathrm{Fe}_{2} \mathrm{O}_{3}\right)$, and magnetite $\left(\mathrm{Fe}_{3} \mathrm{O}_{4}\right)$, have attracted particular attention due to their high theoretical capacity, abundant reserves, low cost, and non-toxicity. ${ }^{[18,19]}$ Take the $\mathrm{Fe}_{2} \mathrm{O}_{3}$ as an example, each formular of $\mathrm{Fe}_{2} \mathrm{O}_{3}$ is able to react with $6 \mathrm{Li}^{+}$, providing a high theoretical capacity of $1007 \mathrm{mAh} \cdot \mathrm{g}^{-1}$. However, the high specific capacity is accompanied by a large volume change ( $\sim 96 \%)$ during lithiation/ de-lithiation. ${ }^{[20]}$ Such a large volume variation results in the notorious problems of active material pulverization, electrode disintegration (loss of electrical contact between active material and current collector), and unstable solid electrolyte interphase (SEI) film formation, eventually leading to rapid capacity fading upon cycling. To achieve high specific capacity without compromising the cyclability, the volume change associated with repeated lithiation/de-lithiation should be better accommodated.

Nanostructure engineering has been demonstrated to be an effective avenue in tackling the volume expansion issue of high-capacity anode materials. The strain induced by lithiation/de-lithiation can be effectively alleviated by proper nanostructure design. Especially, if sufficient pores/voids were introduced in the active material, the volume change of electrode materials can be accommodated as well. Other benefits of nanostructured electrode materials include reduced $\mathrm{Li}^{+}$diffusion lengths and high electrode/electrolyte contact area for $\mathrm{Li}^{+}$flux. ${ }^{[21-23]}$ This review provides a comprehensive summarization of the recent advances on nanostructure engineering of iron oxides for lithium storage. These nanostructures include 0-dimensional (0D) nanoparticles, 1D nanowires/nanorods/nanofibers/nanotubes, 2D nanoflakes/nanosheets, and 3D porous/hollow/hierarchical structures. The structure-electrochemical performance correlations are also discussed.

\section{$\alpha-\mathrm{Fe}_{2} \mathrm{O}_{3}$ based anode materials}

Hematite, also known as $\alpha-\mathrm{Fe}_{2} \mathrm{O}_{3}$, is the most thermodynamically stable form of iron oxide under ambient conditions. ${ }^{[24]}$ It has a corundum structure, in which oxygen adopts a hexagonal close packing while $\mathrm{Fe}$ occupies two-thirds of the octahedral vacancy sites. Despite its high theoretical capacity, $\alpha-\mathrm{Fe}_{2} \mathrm{O}_{3}$ suffers from large volume expansion ( $\sim 96 \%$ ) during lithiation and low intrinsic conductivity. To tackle these issues, it is necessary to design $\alpha-\mathrm{Fe}_{2} \mathrm{O}_{3}$ nanostructures with improved structural stability and electronic conductivity.

\section{$\alpha-\mathrm{Fe}_{2} \mathrm{O}_{3}$ based 1D nanostructures}

1D nanowires, nanorods, nanofibers, and nanotubes possess multiple merits in lithium storage, including large electrode-electrolyte contact area, facile strain relaxation, and efficient $1 \mathrm{D}$ electron transport pathways. ${ }^{[25]}$ In 2006 , Xie et al. reported the first discharge/ charge profiles of $\alpha-\mathrm{Fe}_{2} \mathrm{O}_{3}$ nanorods. ${ }^{[26]}$ Later, Tang's group reported the initial discharge/charge curves of $\alpha-\mathrm{Fe}_{2} \mathrm{O}_{3}{ }^{[27]}$ Although the longterm cycling performances were not provided, these studies suggest that $\alpha-\mathrm{Fe}_{2} \mathrm{O}_{3}$ nanorods could be used as high-capacity LIB anode. Wang et al. studied the electrochemical performances of single crystalline $\alpha-\mathrm{Fe}_{2} \mathrm{O}_{3}$ nanorods with diameters of $60-80 \mathrm{~nm} \cdot{ }^{[28]}$ The

* E-mail: liangzhou@whut.edu.cn,mlq518@whut.edu.cn Received September 28, 2017; accepted November 20, 2017. 
$\alpha-\mathrm{Fe}_{2} \mathrm{O}_{3}$ nanorods demonstrated a high reversible capacity of 955 $\mathrm{mAh} \cdot \mathrm{g}^{-1}$; the capacity decreased to $763 \mathrm{~mA} \cdot \mathrm{h} \cdot \mathrm{g}^{-1}$ after 30 cycles. Recently, Mullins et al. studied the lithium storage performances of hydrothermally synthesized single-crystalline $\alpha-\mathrm{Fe}_{2} \mathrm{O}_{3}$ nanorods with average diameters of $\sim 40 \mathrm{~nm}$ and lengths of $\sim 400 \mathrm{~nm}$. ${ }^{[20]}$ The sample exhibited a stable capacity of $\sim 930 \mathrm{mAh} \cdot \mathrm{g}^{-1}$ from the $2^{\text {nd }}$ to the $30^{\text {th }}$ cycle.

Introducing porosity in $\alpha-\mathrm{Fe}_{2} \mathrm{O}_{3} 1 \mathrm{D}$ nanostructures can further boost their electrochemical performances due to their volume change accommodation and strain relaxation abilities. ${ }^{[29-33]}$ Liu et al. prepared porous single-crystalline $\alpha-\mathrm{Fe}_{2} \mathrm{O}_{3}$ nanorod array on Ti foil by a hydrothermal method followed by annealing. ${ }^{[30]}$ The $\alpha-\mathrm{Fe}_{2} \mathrm{O}_{3}$ nanorod array could be directly used as additive-free LIB anode, delivering a capacity of $562 \mathrm{mAh} \cdot \mathrm{g}^{-1}$ after 50 cycles. Liu, Xu, and co-workers synthesized $\alpha-\mathrm{Fe}_{2} \mathrm{O}_{3}$ porous nanorods with diameters of $30-60 \mathrm{~nm}$ (Figure 1a) through thermal decomposition of $\mathrm{FeC}_{2} \mathrm{O}_{4} \cdot 2 \mathrm{H}_{2} \mathrm{O}$ nanorods. ${ }^{[31]}$ The $\alpha-\mathrm{Fe}_{2} \mathrm{O}_{3}$ porous nanorods delivered a high discharge capacity of $916 \mathrm{mAh} \cdot \mathrm{g}^{-1}$ after 100 cycles at $1 \mathrm{C}(1 \mathrm{C}=1000-1007$ $\left.\mathrm{mA} \cdot \mathrm{g}^{-1}\right)$. Recently, Mai and co-workers fabricated a series of $\alpha-\mathrm{Fe}_{2} \mathrm{O}_{3}$ 1D nanostructures, including hierarchical nanotubes, porous nanotubes, and ladder-like nanostructures (Figures $1 \mathrm{~b}, 1 \mathrm{c}$ ), by a templateengaged redox reaction followed by thermal treatment. ${ }^{[33]}$ The $\alpha-\mathrm{Fe}_{2} \mathrm{O}_{3}$ ladder-like nanostructure delivered a stable capacity of over $1100 \mathrm{mAh} \cdot \mathrm{g}^{-1}$ at $0.1 \mathrm{C}$. Even at a high rate of $5 \mathrm{C}$, the sample exhibited a capacity of $645 \mathrm{mAh} \cdot \mathrm{g}^{-1}$ after 1200 cycles.

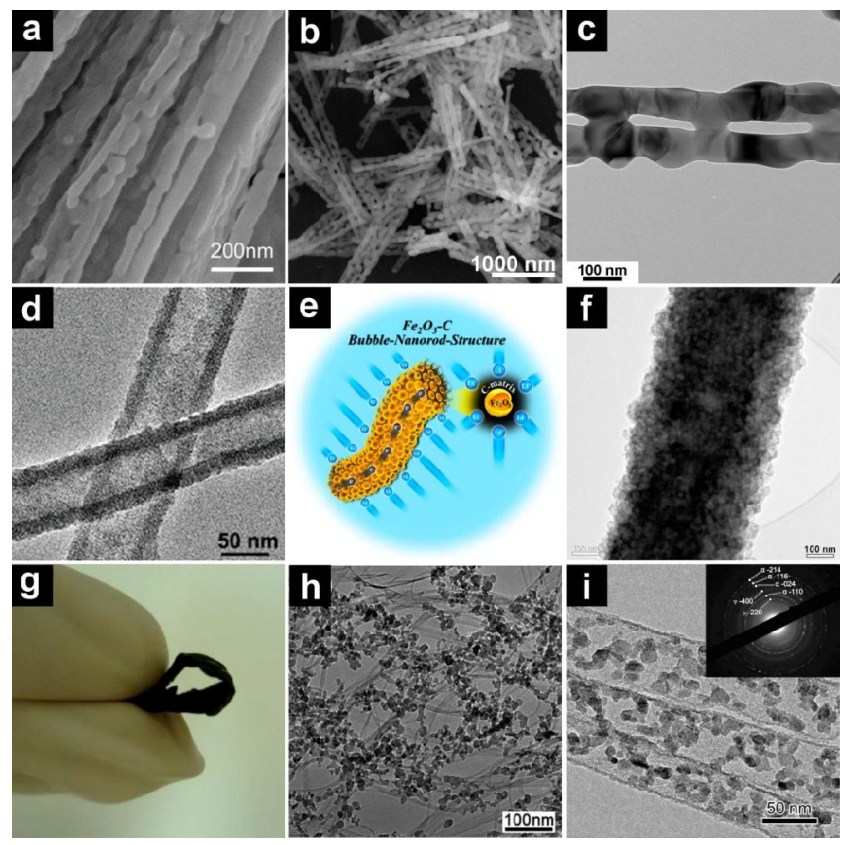

Figure 1 SEM image of $\alpha-\mathrm{Fe}_{2} \mathrm{O}_{3}$ porous nanorods (a) ${ }^{[31]} \mathrm{SEM}$ (b) and TEM (c) images of $\alpha-\mathrm{Fe}_{2} \mathrm{O}_{3}$ ladder-like nanostructure; ${ }^{[33]}$ TEM images of $\alpha-\mathrm{Fe}_{2} \mathrm{O}_{3}$ nanotubes (d) ${ }^{[35]}$ schematic illustration (e) and TEM image (f) of $\alpha-\mathrm{Fe}_{2} \mathrm{O}_{3}$-carbon composite nanofibers constructed by $\alpha-\mathrm{Fe}_{2} \mathrm{O}_{3}$ nanobubbles dispersed in an amorphous carbon matrix $; ;^{[41]}$ digital photo of a flexible $\alpha-\mathrm{Fe}_{2} \mathrm{O}_{3}$-SWCNT membrane (g), TEM image of $\alpha-\mathrm{Fe}_{2} \mathrm{O}_{3}$-SWCNT (h), TEM image of $\mathrm{Fe}_{2} \mathrm{O}_{3}$ nanoparticle filled CNT (i). ${ }^{[44]}$

Nanotubes with efficient $\mathrm{Li}^{+}$diffusion channels and sufficient free space for volume expansion have also been demonstrated to be a promising electrode structure ${ }^{[34-37]}$ In 2005, Chen's group studied the lithium storage performances of $\alpha-\mathrm{Fe}_{2} \mathrm{O}_{3}$ nanotubes prepared by hard templating. ${ }^{[34]}$ The $\alpha-\mathrm{Fe}_{2} \mathrm{O}_{3}$ nanotubes delivered an initial discharge capacity of $1415 \mathrm{mAh} \cdot \mathrm{g}^{-1}$; the capacity decreased to $510 \mathrm{mAh} \cdot \mathrm{g}^{-1}$ after 100 cycles. Using $\mathrm{ZnO}$ nanowire array as the template, Liu and co-workers synthesized vertically aligned $\alpha-\mathrm{Fe}_{2} \mathrm{O}_{3}$ nanotubes on alloy substrate through a "sacrificial template-accelerated hydrolysis" approach. ${ }^{[36]}$ This synthetic strategy could be extended to the preparation of $\alpha-\mathrm{Fe}_{2} \mathrm{O}_{3}-\mathrm{SnO}_{2}$ nanotube array on stainless steel substrate. ${ }^{[38]}$ The obtained nanotube arrays could function as additive-free LIB anode materials. Using $\mathrm{Cu}$ nanowires as the sacrificial templates, Lou et al. prepared $\alpha-\mathrm{Fe}_{2} \mathrm{O}_{3}$ nanotubes with diameters of 50-200 (Figure 1d) ${ }^{[35]}$ The as-obtained $\alpha-\mathrm{Fe}_{2} \mathrm{O}_{3}$ nanotubes exhibited a high specific capacity of over $1000 \mathrm{mAh} \cdot \mathrm{g}^{-1}$ at $0.5 \mathrm{C}$ with excellent cycling stability. Chaudhari and Srinivasan synthesized $\alpha-\mathrm{Fe}_{2} \mathrm{O}_{3}$ hollow nanofibers by electrospinning, which showed a high reversible capacity of 1293 $\mathrm{mAh} \cdot \mathrm{g}^{-1}$ at $0.06 \mathrm{C}$ with good cycling stability. ${ }^{[37]}$

Compositing the 1D $\alpha-\mathrm{Fe}_{2} \mathrm{O}_{3}$ nanostructures with conductive carbon would integrate the advantages of both materials, further boosting the lithium storage performance. ${ }^{[39-42]}$ For example, $\alpha$ $\mathrm{Fe}_{2} \mathrm{O}_{3}$-carbon nanofibers $\left(\alpha-\mathrm{Fe}_{2} \mathrm{O}_{3}-\mathrm{CNF}\right)$ were prepared via electrospinning and evaluated as LIB anode materials by different groups. ${ }^{[39-41]}$ The $\alpha-\mathrm{Fe}_{2} \mathrm{O}_{3}$-carbon composite nanofibers prepared by Fan et al. demonstrated a stable capacity of $\sim 820 \mathrm{mAh} \cdot \mathrm{g}^{-1}$ at $0.2 \mathrm{C}$ for 100 cycles. ${ }^{[40]}$ The $\alpha-\mathrm{Fe}_{2} \mathrm{O}_{3}$-carbon composite nanofibers prepared by Kang's group were constructed by numerous $\alpha-\mathrm{Fe}_{2} \mathrm{O}_{3}$ nanobubbles uniformly dispersed in an amorphous carbon matrix (Figures 1e and 1f). ${ }^{[41]}$ This novel nanostructure delivered a high specific capacity of $\sim 820 \mathrm{mAh} \cdot \mathrm{g}^{-1}$ after 300 cycles at $1 \mathrm{C}$.

$\mathrm{Fe}_{2} \mathrm{O}_{3}$-carbon nanotube $\left(\mathrm{Fe}_{2} \mathrm{O}_{3}\right.$-CNT) composites have also been constructed and evaluated as LIB anode materials. ${ }^{[43-45]}$ The $\mathrm{Fe}_{2} \mathrm{O}_{3}$ nanoparticles can be either decorated on or confined in the CNTs. For example, Li et al. designed an $\alpha-\mathrm{Fe}_{2} \mathrm{O}_{3}$ nanoparticle decorated singlewalled carbon nanotube $\left(\alpha-\mathrm{Fe}_{2} \mathrm{O}_{3}\right.$-SWCNT) membrane with a high $\mathrm{Fe}_{2} \mathrm{O}_{3}$ loading of $88 \mathrm{wt} \%$ (Figures $1 \mathrm{~g}$ and $1 \mathrm{~h}$ ). ${ }^{[43]}$ The $\alpha-\mathrm{Fe}_{2} \mathrm{O}_{3}$ SWCNT membrane can function as a flexible, binder-free, and current-collector-free LIB anode, demonstrating a high reversible capacity of $1243 \mathrm{mAh} \cdot \mathrm{g}^{-1}$ at $0.05 \mathrm{C}$ and a specific capacity of $801 \mathrm{mAh} \cdot \mathrm{g}^{-1}$ after 90 cycles as $0.5 \mathrm{C}$. Liu et al. constructed an $\mathrm{Fe}_{2} \mathrm{O}_{3}$ nanoparticle filled CNT composite $\left(\mathrm{Fe}_{2} \mathrm{O}_{3}-\mathrm{CNT}\right)$ with $\alpha-\mathrm{Fe}_{2} \mathrm{O}_{3}$ as the major phase and $\gamma-\mathrm{Fe}_{2} \mathrm{O}_{3}$ as the minor phase (Figure 1i). ${ }^{[4]}$ A capacity of 811 $\mathrm{mAh} \cdot \mathrm{g}^{-1}$ could be achieved after 100 cycles at $0.035 \mathrm{C}$. The superior electrochemical properties of the $\mathrm{Fe}_{2} \mathrm{O}_{3}$-CNT could be attributed to its unique configuration, where the CNT shell not only improved the electronic conductivity but also prevented the aggregation and exfoliation of the $\mathrm{Fe}_{2} \mathrm{O}_{3}$ nanoparticles during repeated discharge/charge processes.

\section{$\alpha-\mathrm{Fe}_{2} \mathrm{O}_{3}$ based 2D nanostructures}

2D nanoflakes/nanosheets/nanodiscs are able to expand/contract in the direction parallel to the normal of the basal plane during lithiation/de-lithiation. ${ }^{[46-48]}$ In 2006 , Chowdari et al. reported the preparation of $\alpha-\mathrm{Fe}_{2} \mathrm{O}_{3}$ nanoflakes (Figure 2a) on $\mathrm{Cu}$ foil via a thermal treatment method. ${ }^{[46]}$ The $\alpha-\mathrm{Fe}_{2} \mathrm{O}_{3}$ nanoflakes exhibited a stable capacity of $\sim 700 \mathrm{mAh} \cdot \mathrm{g}^{-1}$ at $0.065 \mathrm{C}$ with no noticeable capacity fading for 80 cycles. Using a solvothermal method with subsequent annealing, Lou et al. grew porous $\alpha-\mathrm{Fe}_{2} \mathrm{O}_{3}$ nanosheets (Figure $2 \mathrm{~b}$ ) on various metallic substrates. ${ }^{[47]}$ With highly porous and ultrathin features, the Ti foil supported $\alpha-\mathrm{Fe}_{2} \mathrm{O}_{3}$ nanosheets provided a specific capacity of $908 \mathrm{mAh} \cdot \mathrm{g}^{-1}$ after 60 cycles at $0.1 \mathrm{C}$.

Graphene, a typical 2D material with excellent electronic conductivity, high surface area, mechanical robustness, is an ideal component to couple with $\alpha-\mathrm{Fe}_{2} \mathrm{O}_{3}$ for volume change accommodation and conductivity improvement. ${ }^{[49-60]}$ Therefore, $\alpha-\mathrm{Fe}_{2} \mathrm{O}_{3}$-graphene nanocomposites have been extensively investigated for lithium storage. As a typical example, Ruoff's group prepared an $\alpha-\mathrm{Fe}_{2} \mathrm{O}_{3}$-reduced graphene oxide composite $\left(\alpha-\mathrm{Fe}_{2} \mathrm{O}_{3}-\mathrm{RGO}\right)$, which manifested a reversible capacity of $982 \mathrm{mAh} \cdot \mathrm{g}^{-1}$ with good capacity retention. ${ }^{[49]}$ $\mathrm{Li}$ et al. constructed a monolithic $\alpha-\mathrm{Fe}_{2} \mathrm{O}_{3}$-graphene hybrid (Figures $2 \mathrm{c}$ and $2 \mathrm{~d}$ ) by a hydrothermal approach. ${ }^{[59]}$ The resultant hybrid could be directly used as a free-standing LIB anode, providing a specific 
capacity of $810 \mathrm{mAh} \cdot \mathrm{g}^{-1}$ after 100 cycles at $0.1 \mathrm{C}$. In another study, Wang et al. designed an $\alpha-\mathrm{Fe}_{2} \mathrm{O}_{3}$-CNT-graphene ternary hybrid (Figure 2e) by a chemical vapor deposition (CVD) method. ${ }^{[57]}$ When applied as the anode material for LIBs, the ternary hybrid manifested high specific capacity $\left(984 \mathrm{mAh} \cdot \mathrm{g}^{-1}\right)$, superior cyclability, and high rate capability.

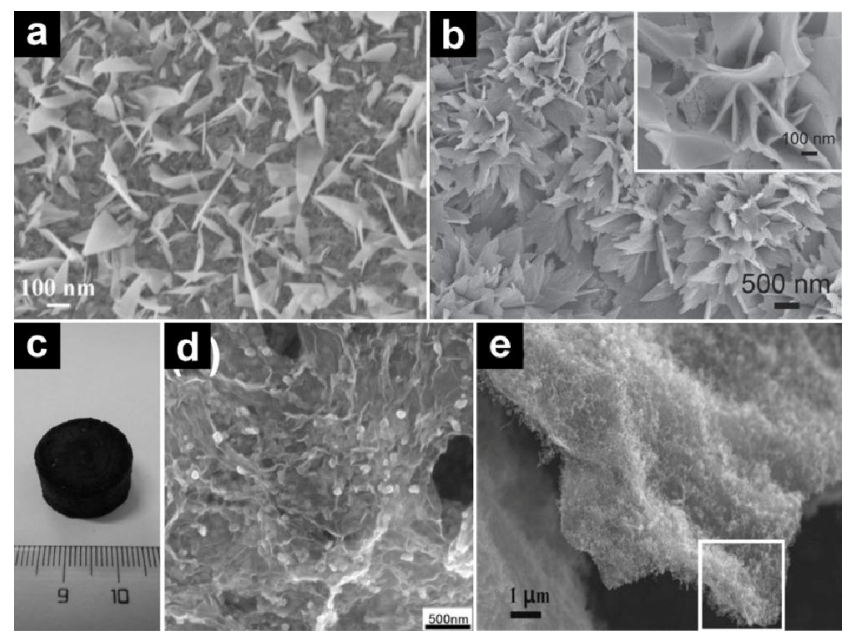

Figure 2 SEM image of $\alpha-\mathrm{Fe}_{2} \mathrm{O}_{3}$ nanoflakes on $\mathrm{Cu}$ foil (a), ${ }^{[46]} \mathrm{SEM}$ image of $\alpha-\mathrm{Fe}_{2} \mathrm{O}_{3}$ nanosheets on Ti foil (b), ${ }^{[47]}$ digital photo of the monolithic $\alpha-\mathrm{Fe}_{2} \mathrm{O}_{3}$-graphene hybrid (c); SEM image of the $\alpha-\mathrm{Fe}_{2} \mathrm{O}_{3}$ graphene hybrid (d), ${ }^{[59]} \mathrm{SEM}$ image of the $\alpha-\mathrm{Fe}_{2} \mathrm{O}_{3}-\mathrm{CNT}$-graphene ternary composite $(\mathrm{e}){ }^{[57]}$

\section{$\alpha-\mathrm{Fe}_{2} \mathrm{O}_{3}$ based 3D nanostructures}

$3 \mathrm{D}$ porous/hollow/hierarchical structures are able to integrate the advantages of both nanosized primary particles and micron-sized secondary assemblies. ${ }^{[61]}$ Among the various 3D architectures, hollow structures attracted the most attention due to their unique merits of hollow cavity for volume change accommodation, reduced lengths for $\mathrm{Li}^{+}$diffusion, and abundant lithium storage sites. ${ }^{[62-66]}$ In 2007, the lithium storage properties of $\alpha-\mathrm{Fe}_{2} \mathrm{O}_{3}$ hollow spindles and microspheres were reported by Tang and co-workers. ${ }^{[67]}$ Later, Xie's group reported the anode performance of $\alpha-\mathrm{Fe}_{2} \mathrm{O}_{3}$ hollow spheres with a mesoporous shell. ${ }^{[68]}$ In 2009, Song et al. reported a Kirkendall-effect-assisted strategy for the fabrication of $\alpha-\mathrm{Fe}_{2} \mathrm{O}_{3}$ (Figures $3 \mathrm{a}$ and $3 \mathrm{~b}$ ) and carbon encapsulated $\alpha-\mathrm{Fe}_{2} \mathrm{O}_{3}\left(\alpha-\mathrm{Fe}_{2} \mathrm{O}_{3} @ \mathrm{C}\right)$ hollow nanoparticles. ${ }^{[69]}$ The synthesis generally involved two steps, the preparation of $\mathrm{Fe}_{3} \mathrm{C} @ \mathrm{C}$ nanoparticles via co-carbonization and the controlled oxidation of $\mathrm{Fe}_{3} \mathrm{C} @ \mathrm{C}$ nanoparticles. During the controlled oxidation, $\mathrm{Fe}_{3} \mathrm{C} @ \mathrm{C}$ was converted into either $\alpha-\mathrm{Fe}_{2} \mathrm{O}_{3} @ \mathrm{C}\left(280{ }^{\circ} \mathrm{C}\right.$ for $\left.5 \mathrm{~h}\right)$ or pure $\alpha-\mathrm{Fe}_{2} \mathrm{O}_{3}$ hollow nanoparticles $\left(280{ }^{\circ} \mathrm{C}\right.$ for $\left.24 \mathrm{~h}\right)$ through nanoscale Kirkendall effect. The outer semi-graphitic carbon shell could solve the volume expansion and aggregation issues of $\alpha-\mathrm{Fe}_{2} \mathrm{O}_{3}$ effectively. As a result, the $\alpha-\mathrm{Fe}_{2} \mathrm{O}_{3} @ \mathrm{C}$ hollow nanoparticles demonstrated significantly improved cyclability when compared to the pristine $\alpha-\mathrm{Fe}_{2} \mathrm{O}_{3}$ hollow nanoparticles.

Hierarchical hollow spheres constructed by nanosheets/nanoneedles were fabricated and evaluated in LIBs by several groups. ${ }^{[70-73]}$ Lou's group developed a quasi-emulsion tempating method for the synthesis of $\alpha-\mathrm{Fe}_{2} \mathrm{O}_{3}$ hollow spheres with sheet-like building blocks, which delivered a capacity of $710 \mathrm{mAh} \cdot \mathrm{g}^{-1}$ after 100 cycles at 0.2 C. ${ }^{[70]}$ The same group also performed a comparative study on the lithium storage performances of hollow and solid $\alpha-\mathrm{Fe}_{2} \mathrm{O}_{3}$ urchin-like spheres (Figures $3 \mathrm{c}$ and $3 \mathrm{~d}$ ). ${ }^{[71]}$ It was found that the hollow $\alpha-\mathrm{Fe}_{2} \mathrm{O}_{3}$ urchin-like spheres manifested better electrochemical performances than the solid counterpart in terms of specific capacity and capacity retention. Zhang, Yan, and co-workers prepared $\alpha-\mathrm{Fe}_{2} \mathrm{O}_{3}$ hierarchical hollow spheres constructed by ultrathin nanosheets (Figures $3 \mathrm{e}$ and $3 \mathrm{f}$ ) via a sacrificial templating process. ${ }^{[72]}$ The product provided a reversible capacity of $920 \mathrm{mAh} \cdot \mathrm{g}^{-1}$, retaining $815 \mathrm{mAh} \cdot \mathrm{g}^{-1}$ after 200 cycles. The superior electrochemical performances were ascribed to the synergistic effect of the hollow structure and ultrathin nanosheets. To further boost the electrochemical performances of $\alpha-\mathrm{Fe}_{2} \mathrm{O}_{3}$ hierarchical hollow spheres, Huh and co-workers fabricated $\alpha-\mathrm{Fe}_{2} \mathrm{O}_{3} @$ polyaniline ( $\alpha-\mathrm{Fe}_{2} \mathrm{O}_{3} @$ PANI) core@shell hierarchical hollow spheres (Figures $3 \mathrm{~g}$ and $3 \mathrm{~h}$ ) through a simultaneous etching and polymerization process. ${ }^{[73]}$ As expected, the $\alpha-\mathrm{Fe}_{2} \mathrm{O}_{3} @$ PANI core@shell yielded significantly enhanced electrochemical performances in terms of cyclability and rate capability, when compared to pristine urchin-like $\alpha-\mathrm{Fe}_{2} \mathrm{O}_{3}$ hierarchical hollow spheres.

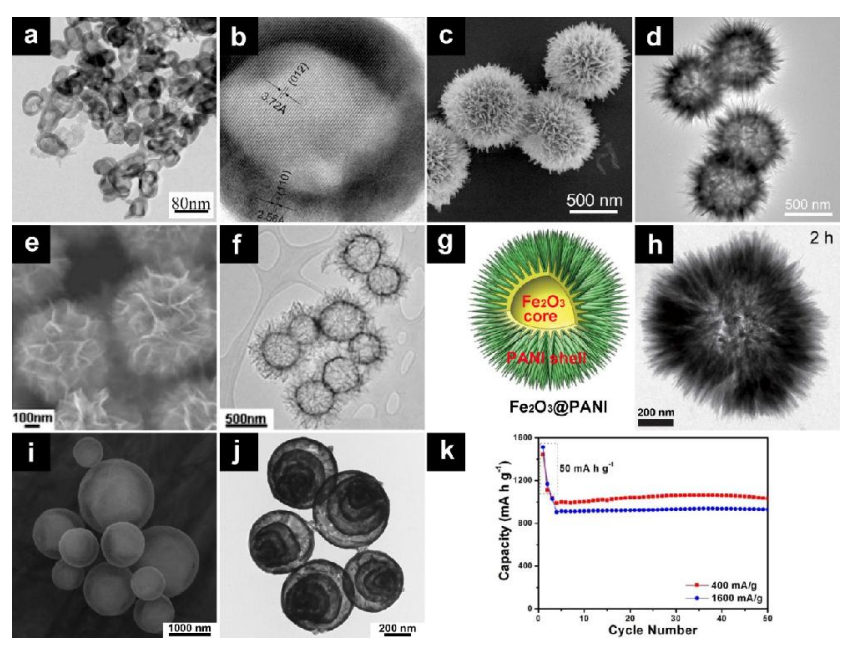

Figure 3 TEM images of $\alpha-\mathrm{Fe}_{2} \mathrm{O}_{3}$ hollow nanoparticles (a, b) ; ${ }^{[69]}$ SEM (c) and TEM (d) images of hollow $\alpha-\mathrm{Fe}_{2} \mathrm{O}_{3}$ urchin-like spheres, ${ }^{[71]}$ SEM (e) and TEM (f) images of $\alpha-\mathrm{Fe}_{2} \mathrm{O}_{3}$ hierarchical hollow spheres constructed by ultrathin nanosheets; ${ }^{[72]}$ schematic illustration (g) and TEM image (h) of $\alpha-\mathrm{Fe}_{2} \mathrm{O}_{3} @$ PANI core@shell hierarchical hollow spheres; ${ }^{[73]}$ SEM (i), TEM (j) images and cycling performances of $\alpha-\mathrm{Fe}_{2} \mathrm{O}_{3}$ multi-shelled hollow spheres. ${ }^{[74]}$

Despite the multiple merits, hollow structures usually suffer from low tap density, which would sacrifice the volumetric energy density when applied in LIBs. In this regard, multi-shelled hollow structures are advantageous over the single-shelled counterparts. Recently, Zhou et al. developed a simple spray drying method for the preparation of $\alpha-\mathrm{Fe}_{2} \mathrm{O}_{3}$ multi-shelled hollow spheres using cheap, widely available iron nitrate and sucrose as the only precursors. ${ }^{[74,75]}$ The obtained $\alpha-\mathrm{Fe}_{2} \mathrm{O}_{3}$ presented a unique quadruple-shelled hollow spherical structure with sizes of 300-3000 nm (Figures 3i and 3j). The non-equilibrium heat treatment induced heterogeneous contraction was responsible for the formation of the multi-shelled hollow structures. When evaluated as the LIB anode material, the $\alpha-\mathrm{Fe}_{2} \mathrm{O}_{3}$ MSHSs delivered stable high capacities of 1000 and $900 \mathrm{mAh} \cdot \mathrm{g}^{-1}$ with no noticeable capacity fading up to 50 cycles at 0.4 and $1.6 \mathrm{C}$, respectively (Figure $3 \mathrm{k}$ ). Similar $\alpha-\mathrm{Fe}_{2} \mathrm{O}_{3}$ multi-shelled hollow structures could be achieved by hard templating ${ }^{[76]}$ and spray pyrolysis. ${ }^{[77]}$

Other $\alpha-\mathrm{Fe}_{2} \mathrm{O}_{3}$-based 3D architectures employed in LIBs include mesoporous $\alpha-\mathrm{Fe}_{2} \mathrm{O}_{3},{ }^{[78-80]}$ porous $\alpha-\mathrm{Fe}_{2} \mathrm{O}_{3},{ }^{[61,81]} \alpha-\mathrm{Fe}_{2} \mathrm{O}_{3} @$ graphitic carbon microspheres, ${ }^{[82]} \alpha-\mathrm{Fe}_{2} \mathrm{O}_{3} @ \mathrm{C}$ hierarchical tubular structures (a), ${ }^{[83]} \alpha-\mathrm{Fe}_{2} \mathrm{O}_{3} @ \mathrm{C}$ hollow nanohorns on CNT (Figure 4b), ${ }^{[84]}$ hierarchical $\mathrm{SnO}_{2}-\mathrm{Fe}_{2} \mathrm{O}_{3}$ heterostructures, ${ }^{[85]}$ hierarchical $\mathrm{TiO}_{2} @ \alpha-\mathrm{Fe}_{2} \mathrm{O}_{3}$ hollow structures (Figure $4 \mathrm{c}$ ), ${ }^{[86]}$ branched $\mathrm{TiO}_{2}-\mathrm{B} @ \alpha-\mathrm{Fe}_{2} \mathrm{O}_{3}$ heterostructures (Figure 4d), ${ }^{[87]}$ branched $\mathrm{SnO}_{2} @ \alpha-\mathrm{Fe}_{2} \mathrm{O}_{3}$ heterostructures (Figure 4e), ${ }^{[8]}$ and branched $\beta-\mathrm{MnO}_{2} @ \alpha-\mathrm{Fe}_{2} \mathrm{O}_{3}$ heterostructures (Figure 4f). ${ }^{[89]}$ All these 3D architectures demonstrated impressive lithium storage performances. 


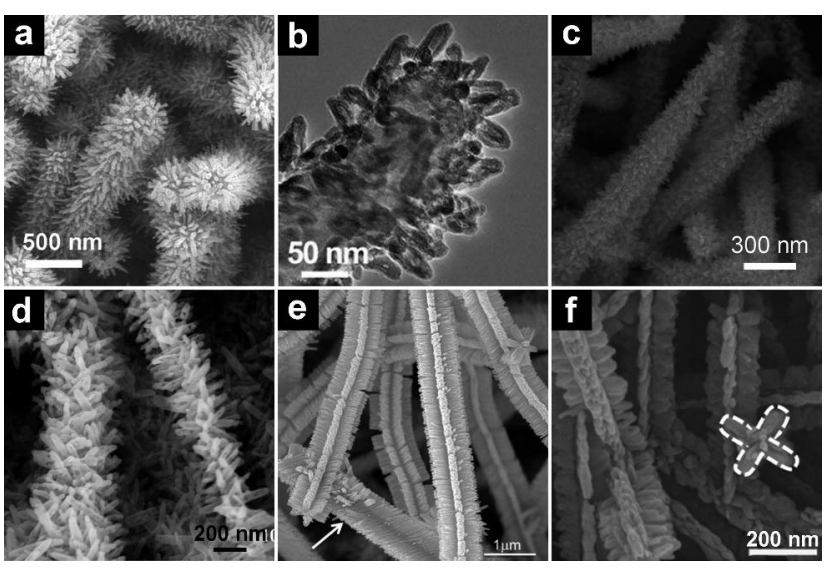

Figure 4 SEM image of $\alpha-\mathrm{Fe}_{2} \mathrm{O}_{3} @ \mathrm{C}$ hierarchical tubular structures (a), ${ }^{[83]}$ TEM image of $\alpha-\mathrm{Fe}_{2} \mathrm{O}_{3} @ \mathrm{C}$ hollow nanohorns on CNT (b), ${ }^{[84]}$ SEM image of $\mathrm{TiO}_{2} @ \alpha-\mathrm{Fe}_{2} \mathrm{O}_{3}$ hollow structures (c) ${ }^{[86]}$ SEM image of branched $\mathrm{TiO}_{2}-\mathrm{B} @ \alpha-\mathrm{Fe}_{2} \mathrm{O}_{3}$ heterostructures (d), ${ }^{[87]}$ SEM image of branched $\mathrm{SnO}_{2} @ \alpha-\mathrm{Fe}_{2} \mathrm{O}_{3}$ heterostructures (e), ${ }^{[88]}$ SEM image of branched $\beta-\mathrm{MnO}_{2} @ \alpha-\mathrm{Fe}_{2} \mathrm{O}_{3}$ heterostructures (f). ${ }^{[89]}$

\section{$\mathrm{V}-\mathrm{Fe}_{2} \mathrm{O}_{3}$ based anode materials}

$\gamma-\mathrm{Fe}_{2} \mathrm{O}_{3}$ adopts a cubic crystal structure with $\mathrm{FD} \overline{3} \mathrm{~m}$ space group. In the unit cell, the $\mathrm{Fe}^{3+}$ ions occupy the octahedral $16 \mathrm{~d}$ and tetrahedral 8a sites with different chemical states. Compared to the numerous publications on $\alpha-\mathrm{Fe}_{2} \mathrm{O}_{3}$ based anode materials, the reports on $\gamma-\mathrm{Fe}_{2} \mathrm{O}_{3}$ based anode materials are much less, probably due to its poor stability.

\section{Gamma- $\mathrm{Fe}_{2} \mathrm{O}_{3}$ based $1 \mathrm{D}$ nanostructures}

The 1D $\gamma-\mathrm{Fe}_{2} \mathrm{O}_{3}$ based anode materials include $\mathrm{Fe}_{2} \mathrm{O}_{3}$ nanotubes, ${ }^{[90]} \mathrm{Fe}_{2} \mathrm{O}_{3}-\mathrm{CNT}$ hybrids, ${ }^{[42,91]}$ and $\gamma-\mathrm{Fe}_{2} \mathrm{O}_{3}$-carbon nanofiber. ${ }^{[92-94]}$ Son reported the synthesis of $1 \mathrm{D} \mathrm{Fe}_{2} \mathrm{O}_{3}$ nanotubes $\left(\gamma-\mathrm{Fe}_{2} \mathrm{O}_{3}\right.$ as the dominant phase and $\alpha-\mathrm{Fe}_{2} \mathrm{O}_{3}$ as the minor phase) with particulate walls using microporous organic tubes as the templates. ${ }^{[90]}$ The resultant $\mathrm{Fe}_{2} \mathrm{O}_{3}$ nanotubes delivered a discharge capacity of $950 \mathrm{mAh} \cdot \mathrm{g}^{-1}$ for the second cycle, maintaining $929 \mathrm{mAh} \cdot \mathrm{g}^{-1}$ after 30 cycles. Liu et al. designed an $\mathrm{Fe}_{2} \mathrm{O}_{3}-\mathrm{CNT}$ nanocomposite $\left(\gamma-\mathrm{Fe}_{2} \mathrm{O}_{3}\right.$ as the dominant phase and $\alpha-\mathrm{Fe}_{2} \mathrm{O}_{3}$ as the minor phase) with $9 \mathrm{~nm}-\mathrm{Fe}_{2} \mathrm{O}_{3}$ nanoparticles homogeneously filled in the hollow interiors of CNTs. ${ }^{[42]}$ The $\mathrm{Fe}_{2} \mathrm{O}_{3}-\mathrm{NT}$ nanocomposite showed a specific capacity of $768 \mathrm{mAh} \cdot \mathrm{g}^{-1}$ after 40 cycles. Cheng and co-workers fabricated two types of $\gamma$ - $\mathrm{Fe}_{2} \mathrm{O}_{3}-\mathrm{CNT}$ hybrids, $\gamma-\mathrm{Fe}_{2} \mathrm{O}_{3}$ nanoparticle-filled CNT (Figure 5a) and $\gamma-\mathrm{Fe}_{2} \mathrm{O}_{3}$ nanoparticle-coated CNT (Figure 5b). ${ }^{[91]}$ The $\gamma-\mathrm{Fe}_{2} \mathrm{O}_{3}$ nanoparticle-coated CNT with an $\mathrm{Fe}_{2} \mathrm{O}_{3}$ mass ratio of $45 \%$ exhibited a reversible capacity of $1092 \mathrm{mAh} \cdot \mathrm{g}^{-1}$ at $50 \mathrm{~mA} \cdot \mathrm{g}^{-1}$; the capacity decreased to $867 \mathrm{mAh} \cdot \mathrm{g}^{-1}$ after 16 cycles. Meanwhile, the $\gamma-\mathrm{Fe}_{2} \mathrm{O}_{3}$ nanoparticle-filled $\mathrm{CNT}$ with a $\mathrm{Fe}_{2} \mathrm{O}_{3}$ weight ratio of $20 \%$ delivered a reversible capacity of $1144 \mathrm{mAh} \cdot \mathrm{g}^{-1}$; the capacity tended to stabilize at $964 \mathrm{mAh} \cdot \mathrm{g}^{-1}$ after 16 cycles. By combining electrospinning, hydrothermal treatment, and post annealing, Reddy et al. fabricated a $\gamma-\mathrm{Fe}_{2} \mathrm{O}_{3}$-carbon nanofiber hybrid. ${ }^{[92]}$ At a current density of 50 $\mathrm{mA} \cdot \mathrm{g}^{-1}$, the $\gamma-\mathrm{Fe}_{2} \mathrm{O}_{3}-\mathrm{CNF}$ hybrid delivered a specific capacity of 830 $\mathrm{mAh} \cdot \mathrm{g}^{-1}$ after 40 cycles.

\section{$\gamma-\mathrm{Fe}_{2} \mathrm{O}_{3}$ based $2 \mathrm{D}$ nanostructures}

The reports on $\gamma-\mathrm{Fe}_{2} \mathrm{O}_{3}$ based 2D nanostructured anodes are relatively rare. ${ }^{[95-97]}$ Lee et al. reported a $\gamma-\mathrm{Fe}_{2} \mathrm{O}_{3}-\mathrm{C}$ porous microdisc anode material (Figure $5 \mathrm{c}$ ). ${ }^{[95]}$ The synthesis involved two steps: hydrothermal synthesis of $\alpha-\mathrm{Fe}_{2} \mathrm{O}_{3}$ porous discs and CVD posttreatment in acetylene atmosphere. During the CVD treatment, the $\alpha-\mathrm{Fe}_{2} \mathrm{O}_{3}$ was converted into $\gamma-\mathrm{Fe}_{2} \mathrm{O}_{3}$ and a thin carbon shell was coated onto the surface of the sample. The combination of abundant porosity and thin carbon coating provided fast diffusion for both $\mathrm{Li}$ and electrons. A high capacity of over $900 \mathrm{mAh} \cdot \mathrm{g}^{-1}$ could be achieved after 40 cycles at $0.1 \mathrm{C}$. A $\gamma-\mathrm{Fe}_{2} \mathrm{O}_{3}-\mathrm{RGO}$ composite was fabricated by Yushin and co-workers (Figure 5d). ${ }^{[97]}$ The $\gamma-\mathrm{Fe}_{2} \mathrm{O}_{3}$ RGO composite exhibited a high specific capacity of $690 \mathrm{mAh} \cdot \mathrm{g}^{-1}$ after 100 cycles at $0.5 \mathrm{C}$.
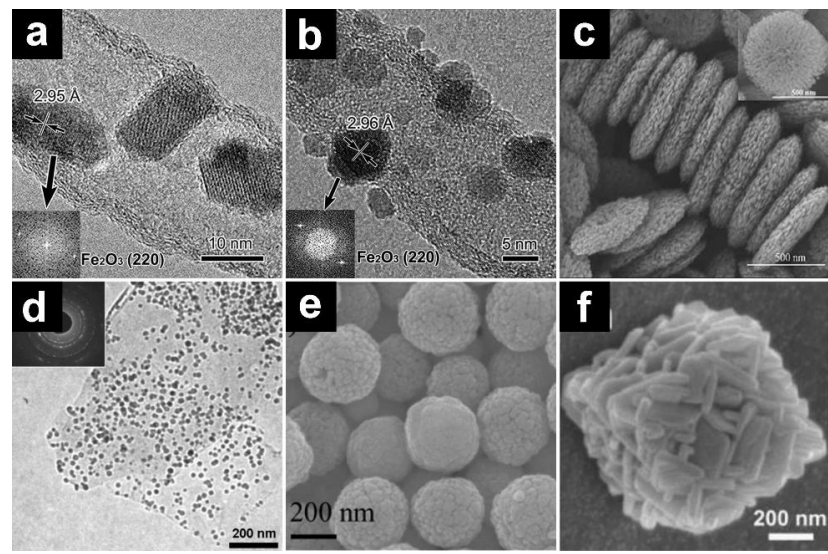

Figure 5 TEM images of $\gamma-\mathrm{Fe}_{2} \mathrm{O}_{3}$ nanoparticle-filled CNT (a) and $\gamma-\mathrm{Fe}_{2} \mathrm{O}_{3}$ nanoparticle-coated CNT (b); ${ }^{[91]} \mathrm{SEM}$ image of $\gamma-\mathrm{Fe}_{2} \mathrm{O}_{3}-\mathrm{C}$ porous microdiscs (c); ${ }^{[95]} \mathrm{TEM}$ image of $\gamma-\mathrm{Fe}_{2} \mathrm{O}_{3}$-graphene composite (d); ${ }^{[97]} \mathrm{SEM}$ image of $N$-doped carbon coated $\gamma-\mathrm{Fe}_{2} \mathrm{O}_{3}$ spheres (e); ${ }^{[100]}$ SEM image of $\mathrm{Fe}_{2} \mathrm{O}_{3}$ hierarchical hollow microbox (f). ${ }^{[102]}$

\section{$\gamma-\mathrm{Fe}_{2} \mathrm{O}_{3}$ based 3D nanostructures}

A variety of $\gamma-\mathrm{Fe}_{2} \mathrm{O}_{3}$ based $3 \mathrm{D}$ architectures have been applied in lithium storage, including $\gamma-\mathrm{Fe}_{2} \mathrm{O}_{3}$ microspheres, ${ }^{[98,99]} \mathrm{N}$-doped carbon coated $\gamma-\mathrm{Fe}_{2} \mathrm{O}_{3}$ spheres (Figure 5e), ${ }^{[100]} \gamma-\mathrm{Fe}_{2} \mathrm{O}_{3}$ hollow nanoparticles, ${ }^{[101]} \mathrm{Fe}_{2} \mathrm{O}_{3}$ hierarchical hollow microboxes (Figure 5f), ${ }^{[102,103]}$ hollow $\gamma-\mathrm{Fe}_{2} \mathrm{O}_{3} @$ graphene core@shell hybrid, ${ }^{[104]}$ polypyrrole coated $\gamma-\mathrm{Fe}_{2} \mathrm{O}_{3}$-ordered mesoporous carbon, ${ }^{[105]}$ and double-shelled $\mathrm{Fe}_{2} \mathrm{O}_{3}$ $\mathrm{Co}_{3} \mathrm{O}_{4}$ hollow microcubes. ${ }^{[106]}$ For example, monodisperse $\gamma-\mathrm{Fe}_{2} \mathrm{O}_{3}$ mesoporous spheres were fabricated by a surfactant-free solvothermal method with subsequent thermal transformation. ${ }^{[99]}$ The resultant $\gamma$ - $\mathrm{Fe}_{2} \mathrm{O}_{3}$ mesoporous spheres with an average diameter of $6 \mu \mathrm{m}$ were composed of numerous irregular shaped nanoparticles. When explored as the anode material for LIBs, the $\gamma-\mathrm{Fe}_{2} \mathrm{O}_{3}$ mesoporous microspheres exhibited a high initial capacity of $1453 \mathrm{mAh} \cdot \mathrm{g}^{-1}$, retaining $\sim 700 \mathrm{mAh} \cdot \mathrm{g}^{-1}$ after 110 cycles. Ding and co-workers designed a $N$-doped carbon $\gamma$ - $\mathrm{Fe}_{2} \mathrm{O}_{3}$ sphere anode (Figure 5e) with high specific capacity, stable cycling, and excellent rate capability. ${ }^{[100]} \mathrm{A}$ high capacity of $870 \mathrm{mAh} \cdot \mathrm{g}^{-1}$ could be achieved after 150 cycles at $0.5 \mathrm{C}$. Lu's group designed a delicate polypyrrole coated $\gamma$ - $\mathrm{Fe}_{2} \mathrm{O}_{3}$-ordered mesoporous carbon composite. ${ }^{[105]}$ Ordered mesoporous carbon was firstly synthesized via a nanocasting method, and $\gamma-\mathrm{Fe}_{2} \mathrm{O}_{3}$ nanoparticles were then loaded into the mesoporous carbon through wet impregnation and thermal decomposition. The polypyrrole coating was achieved by vapor-phase polymerization. When applied as the LIB anode, this novel nanocomposite delivered a capacity of $785 \mathrm{mAh} \cdot \mathrm{g}^{-1}$ after 100 cycles at $0.2 \mathrm{C}$. The superior anode performance could be ascribed to the synergistic effect of mesoporous carbon matrix and polypyrrole sealing layer.

\section{Magnetite based anode materials}

$\mathrm{Fe}_{3} \mathrm{O}_{4}$ has an inverse spinel crystal structure. Compared to $\alpha-\mathrm{Fe}_{2} \mathrm{O}_{3}$ and $\gamma-\mathrm{Fe}_{2} \mathrm{O}_{3}, \mathrm{Fe}_{3} \mathrm{O}_{4}$ possesses significantly enhanced electronic conductivity, which is only an order of magnitude lower than the minimum metallic conductivity. ${ }^{[107]}$ Theoretically, each formular of $\mathrm{Fe}_{3} \mathrm{O}_{4}$ may react with $8 \mathrm{Li}^{+}$, giving rise to a high capacity of 926 $\mathrm{mAh} \cdot \mathrm{g}^{-1}$. 


\section{$\mathrm{Fe}_{3} \mathrm{O}_{4}$-based 0D nanostructures}

Important progress has been made in the synthesis and lithium storage performance of $\mathrm{Fe}_{3} \mathrm{O}_{4}$ based nanoparticles during the last decade. ${ }^{[108-111]}$ For example, Guo, Song, and co-workers developed a beaker-in-autoclave setup for the synthesis of highly disperse $\mathrm{Fe}_{3} \mathrm{O}_{4}$ nanoparticles. ${ }^{[108]}$ Although the obtained $\mathrm{Fe}_{3} \mathrm{O}_{4}$ nanoparticles exhibited a reversible capacity of over $600 \mathrm{mAh} \cdot \mathrm{g}^{-1}$, the capacity decreased to $30 \mathrm{mAh} \cdot \mathrm{g}^{-1}$ after only 30 cycles. After carbon encapsulation, the cycling performance could be significantly enhanced; a stable capacity of above $600 \mathrm{mAh} \cdot \mathrm{g}^{-1}$ could be achieved. In another example, Zhao et al. fabricated carbon nanosphere $(\sim 60 \mathrm{~nm})$ encapsulated $\mathrm{Fe}_{3} \mathrm{O}_{4}$ nanocrystals $(\sim 9 \mathrm{~nm})$ through a facile hydrothermal treatment-annealing process (Figure 6a). ${ }^{[9]}$ The composite nanospheres manifested high specific capacities of 784, 568, and 379 $\mathrm{mAh} \cdot \mathrm{g}^{-1}$ at 1,5 , and $10 \mathrm{C}\left(1 \mathrm{C}=924 \mathrm{~mA} \cdot \mathrm{g}^{-1}\right)$, respectively.

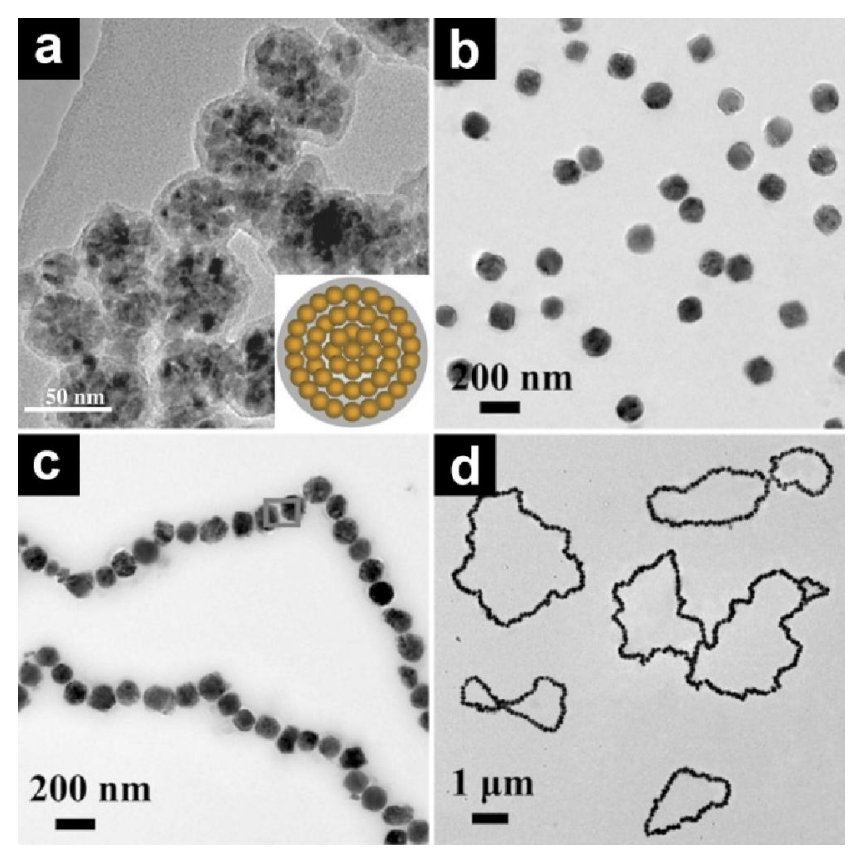

Figure 6 TEM image and schematic structure (inset) of carbon nanosphere encapsulated $\mathrm{Fe}_{3} \mathrm{O}_{4}$ nanocrystals (a) ${ }^{\left[{ }^{[9]}\right.}$ TEM images of $\mathrm{Fe}_{3} \mathrm{O}_{4} @ \mathrm{C}$ core-shell nanospheres (b), chains (c), and rings (d). ${ }^{[13]}$

Due to their interesting ferromagnetic properties, the $0 \mathrm{D} \mathrm{Fe}_{3} \mathrm{O}_{4}$ based nanoparticles can be further assembled into chains and rings. ${ }^{[112,113]}$ Wang, Su, and co-workers synthesized monodisperse $\mathrm{Fe}_{3} \mathrm{O}_{4} @ \mathrm{C}$ core-shell spheres (Figure 6b) using eccentric $\mathrm{Fe}_{2} \mathrm{O}_{3} @$ poly(acrylic acid) core-shell nanoparticles as the precursor. ${ }^{[113]} \mathrm{By}$ adjusting the reaction temperature and time, $\mathrm{Fe}_{3} \mathrm{O}_{4} @ \mathrm{C}$ core-shell chains (Figure 6c) and rings (Figure 6d) could also be obtained. When tested as anode materials for LIBs, the $\mathrm{Fe}_{3} \mathrm{O}_{4} @ \mathrm{C}$ core-shell chains and rings delivered capacities of 780-800 $\mathrm{mAh} \cdot \mathrm{g}^{-1}$ after 100 cycles at $200 \mathrm{~mA} \cdot \mathrm{g}^{-1}$, much higher than that of $\mathrm{Fe}_{3} \mathrm{O}_{4} @ \mathrm{C}$ core-shell nanospheres.

\section{$\mathrm{Fe}_{3} \mathrm{O}_{4}$-based 1D nanostructures}

More than a decade ago, $\mathrm{Fe}_{3} \mathrm{O}_{4}$ had been electrochemically deposited onto $\mathrm{Cu}$ nanorod arrays for lithium storage. ${ }^{[107]}$ The self-supported $\mathrm{Cu}$-nanorod $\mathrm{Fe}_{3} \mathrm{O}_{4}$ electrode demonstrated excellent rate capability. When compared to planar electrodes, the power density could be improved by a factor of six. Since then, much attention has been paid to $1 \mathrm{D} \mathrm{Fe}_{3} \mathrm{O}_{4}$ based nanostructures for lithium storage. ${ }^{[114-121]}$ $\mathrm{Fe}_{3} \mathrm{O}_{4}$ based 1D nanofibers/nanotubes can be facilely prepared via electrospinning. ${ }^{[122-126]}$ Chen et al. prepared $\mathrm{Fe}_{3} \mathrm{O}_{4}-\mathrm{C}$ composite nanofibers via electrospinning ferric acetylacetonate and polyacrylonitrile (PAN) with subsequent annealing. ${ }^{[122]} \mathrm{A}$ high specific capacity of $1007 \mathrm{mAh} \cdot \mathrm{g}^{-1}$ could be obtained after 80 cycles at $200 \mathrm{~mA} \cdot \mathrm{g}^{-1}$. The electrospinning technique can be easily extended to the fabrication of $\mathrm{Fe}_{3} \mathrm{O}_{4}-\mathrm{C}$ hollow nanofibers ${ }^{[123,124]} \mathrm{Fe}_{3} \mathrm{O}_{4}-\mathrm{TiO}_{2}$ nanofiber, ${ }^{[125]}$ and $N$-doped amorphous carbon coated $\mathrm{Fe}_{3} \mathrm{O}_{4}-\mathrm{SnO}_{2}$ coaxial nanofibers (Figure 7a). ${ }^{[126]}$

Carbon nanotubes (CNTs) have been extensively used as the backbone material to construct $\mathrm{Fe}_{3} \mathrm{O}_{4}$ based 1D nanostructures. ${ }^{[127-131]}$ For example, Dillon et al. designed a binder-free $\mathrm{Fe}_{3} \mathrm{O}_{4}$ nanorodSWCNT electrode (Figure 7b) through a two-step vacuum filtrationreduction process. ${ }^{[127]}$ Impressively, the binder-free electrode with 95 $\mathrm{wt} \% \mathrm{Fe}_{3} \mathrm{O}_{4}$ and $5 \mathrm{wt} \%$ SWCNT demonstrated high reversible capacities of $\sim 1000,800$, and $600 \mathrm{mAh} \cdot \mathrm{g}^{-1}$ at 1,5 , and $10 \mathrm{C}$, respectively. By integrating CNT drawing and magnetron sputtering, Wang et al. obtained $\mathrm{Fe}_{3} \mathrm{O}_{4}$-CNT electrodes. ${ }^{[128]}$ The $\mathrm{Fe}_{3} \mathrm{O}_{4}$ nanoparticles with sizes of 5-7 nm were uniformly sputtered on aligned CNTs, forming a core-sheath structure (Figures $7 \mathrm{c}$ and $7 \mathrm{~d}$ ). The free-standing $\mathrm{Fe}_{3} \mathrm{O}_{4}$-CNT electrode delivered a specific capacity of over 800 $\mathrm{mAh} \cdot \mathrm{g}^{-1}$ based on the total mass of the electrode. Benefitting from the outstanding electronic conductivity of CNTs, the electrode also demonstrated excellent rate capability.

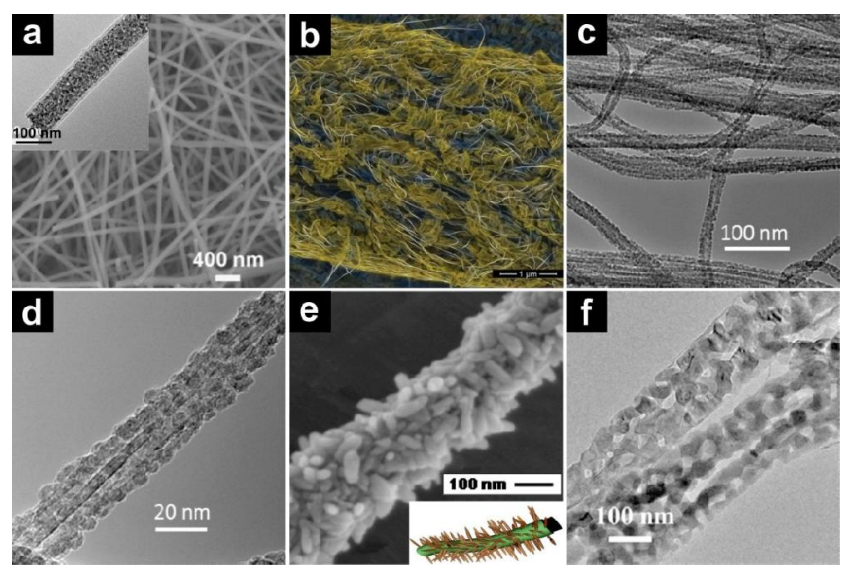

Figure 7 SEM and TEM (inset) images of $N$-doped amorphous carbon coated $\mathrm{Fe}_{3} \mathrm{O}_{4}-\mathrm{SnO}_{2}$ coaxial nanofibers (a); ${ }^{[126]}$ colorized SEM image of $\mathrm{Fe}_{3} \mathrm{O}_{4}$ nanorod-SWC NT composite (b); ${ }^{[127]}$ TEM images of core-sheath structured $\mathrm{Fe}_{3} \mathrm{O}_{4}$-CNT composites (c, d) ${ }^{[128]}$ SEM image and schematic illustration of $\mathrm{Fe}_{3} \mathrm{O}_{4}-\mathrm{TiO}_{2}-\mathrm{C}$ composite nanofibers (e) $;{ }^{[132]}$ and TEM image of porous $\mathrm{Fe}_{3} \mathrm{O}_{4}-\mathrm{VO}_{x}$-graphene ternary nanowires (f). ${ }^{[136]}$

Cellulose nanofibers and other 1D nanostructures can also be employed as the scaffold material or sacrificial templates to prepare 1D $\mathrm{Fe}_{3} \mathrm{O}_{4}$ based nanofibers/nanowires/nanotubes. ${ }^{[132-136]}$ Huang et al. constructed $\mathrm{Fe}_{3} \mathrm{O}_{4}-\mathrm{TiO}_{2}-\mathrm{C}$ composite nanofibers (Figure 7e) by employing natural cellulose as the scaffold. ${ }^{[132]}$ The ternary composite exhibited a stable capacity of $\sim 525 \mathrm{mAh} \cdot \mathrm{g}^{-1}$ at $100 \mathrm{~mA} \cdot \mathrm{g}^{-1}$. By anchoring $\mathrm{Fe}_{2} \mathrm{O}_{3}$ nanoparticles on bacterial cellulose nanofiber followed by carbonization, Luo and co-workers obtained a flexible, binder-free $\mathrm{Fe}_{3} \mathrm{O}_{4}$-carbon nanofiber electrode. ${ }^{[133]}$ By electrochemical deposition of $\mathrm{Fe}_{3} \mathrm{O}_{4}$ on $\mathrm{CuO}$ nanoneedle arrays, Yan et al. obtained coaxial $\mathrm{CuO} @ \mathrm{Fe}_{3} \mathrm{O}_{4}$ hybrid nanowire electrode. ${ }^{[134]} \mathrm{Lu}$ 's group reported the synthesis of carbon coated $\mathrm{Fe}_{3} \mathrm{O}_{4}$ nanotubes by using $\alpha-\mathrm{MoO}_{3}$ nanorods as the hard template. ${ }^{[135]}$ An et al. synthesized porous $\mathrm{Fe}_{3} \mathrm{O}_{4}$ amorphous vanadium oxide-graphene $\left(\mathrm{Fe}_{3} \mathrm{O}_{4}-\mathrm{VO}_{x}\right.$-graphene) ternary nanowires (Figure $7 \mathrm{f}$ ) by reducing graphene decorated iron vanadate $\left(\mathrm{FeVO}_{4} \cdot 1.1 \mathrm{H}_{2} \mathrm{O}\right)$ nanowires in $5 \% / 95 \% \mathrm{H}_{2} / \mathrm{Ar}^{[136]}$ 


\section{$\mathrm{Fe}_{3} \mathrm{O}_{4}$-based 2D nanostructures}

$\mathrm{Fe}_{3} \mathrm{O}_{4}$-graphene nanocomposite is the most extensively studied $\mathrm{Fe}_{3} \mathrm{O}_{4}$-based 2D nanostructures. ${ }^{[137-149]}$ In 2010, Cheng's group designed a graphene nanosheets wrapped $\mathrm{Fe}_{3} \mathrm{O}_{4}$ (Figures 8a and 8b) anode. ${ }^{[137]}$ In the constructed $\mathrm{Fe}_{3} \mathrm{O}_{4}$-graphene composite, the graphene nanosheets not only buffered the volume change of $\mathrm{Fe}_{3} \mathrm{O}_{4}$, but also acted as the electron highway; the $\mathrm{Fe}_{3} \mathrm{O}_{4}$ particles prevented the restacking of graphene; meanwhile, the porosity between $\mathrm{Fe}_{3} \mathrm{O}_{4}$ and graphene provided efficient $\mathrm{Li}^{+}$diffusion channels. As a result, the resultant $\mathrm{Fe}_{3} \mathrm{O}_{4}$-graphene nanocomposite delivered a specific capacity of $580 \mathrm{mAh} \cdot \mathrm{g}^{-1}$ after 100 cycles at $700 \mathrm{~mA} \cdot \mathrm{g}^{-1}$ (Figure $8 \mathrm{c}$ ). More recently, an intriguing $\mathrm{Fe}_{3} \mathrm{O}_{4}$ nanoparticle- $\mathrm{TiO}_{2}$ nanorod-graphene sheet $\left(\mathrm{Fe}_{3} \mathrm{O}_{4}-\mathrm{TiO}_{2}\right.$-Graphene) ternary hetero-structured anode was reported by Liu, Xie, and co-workers (Figures $8 \mathrm{~d}$ and 8e). ${ }^{[148]}$ The $\mathrm{Fe}_{3} \mathrm{O}_{4}-\mathrm{TiO}_{2}$-Graphene ternary composite delivered a reversible capacity of $\sim 330 \mathrm{mAh} \cdot \mathrm{g}^{-1}$ at $1000 \mathrm{~mA} \cdot \mathrm{g}^{-1}$ (Figure $8 \mathrm{f}$ )
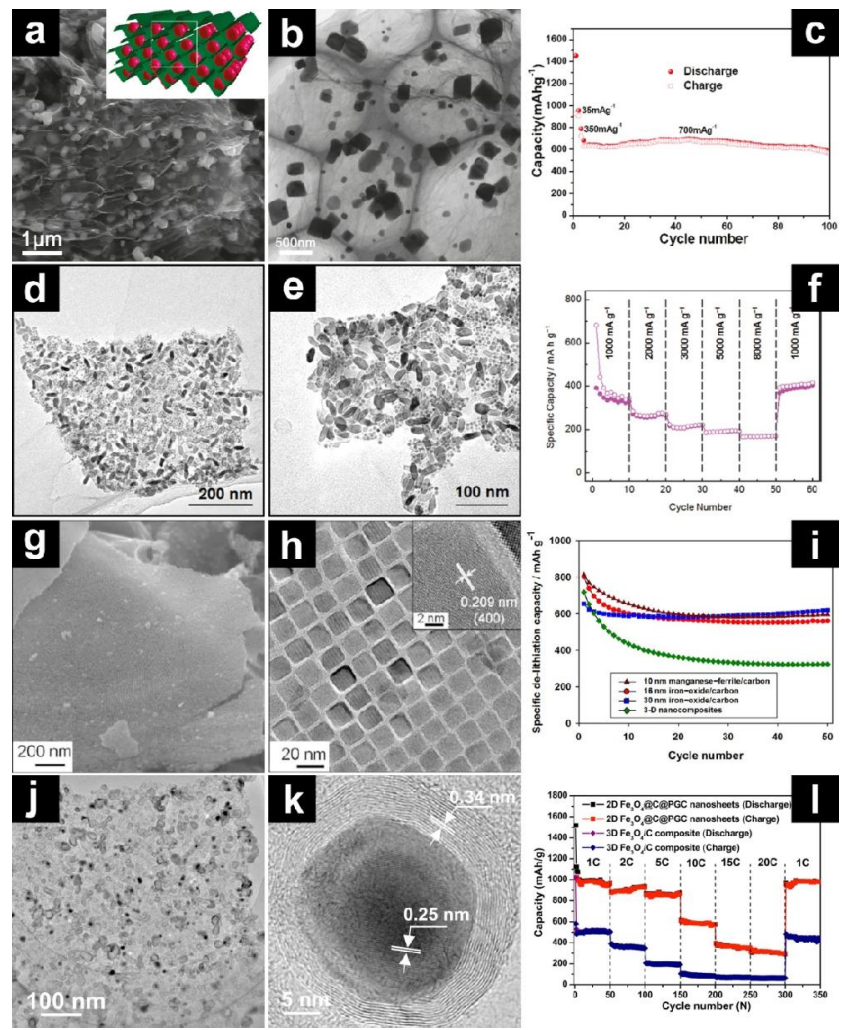

Figure 8 Schematic illustration (inset), SEM image (a), TEM image (b) and cycling performance (c) of $\mathrm{Fe}_{3} \mathrm{O}_{4}$-graphene nanocomposite, ${ }^{[137]}$ TEM images (d, e) and rate performance (f) of $\mathrm{Fe}_{3} \mathrm{O}_{4}-\mathrm{TiO}_{2}$ graphene ternary hetero-structures $;{ }^{[148]}$ SEM image (g), TEM image (h), and cycling performance (i) of $\mathrm{Fe}_{3} \mathrm{O}_{4}$ nanocrystal-carbon hybrid nanosheets; ${ }^{[150]}$ TEM image (j), high-resolution TEM (k) image, and rate performance (l) of $\mathrm{Fe}_{3} \mathrm{O}_{4}$ nanoparticle-graphitic carbon hybrid nanosheets. ${ }^{[151]}$

2D $\mathrm{Fe}_{3} \mathrm{O}_{4}-\mathrm{C}$ hybrid nanosheets have also been prepared for lithium storage. ${ }^{[150-152]}$ Hyeon, Piao, and co-workers presented a simple and direct synthetic approach for the fabrication of $\mathrm{Fe}_{3} \mathrm{O}_{4}$ nanocrystal-carbon hybrid nanosheets (Figures $8 \mathrm{~g}$ and $8 \mathrm{~h}$ ) using ferric oleate complex as the precursor for both $\mathrm{Fe}_{3} \mathrm{O}_{4}$ and carbon. ${ }^{[150]}$ Sodium sulfate was used as the template for producing the $2 \mathrm{D}$ nanosheet structures. Interestingly, the $\mathrm{Fe}_{3} \mathrm{O}_{4}$ nanocrystals embedded in the carbon nanosheets were very uniform and their size could be well controlled by tuning the heating rate and temperature. The $2 \mathrm{D} \mathrm{Fe}_{3} \mathrm{O}_{4}$ nanocrystal-carbon hybrid nanosheets exhibited stable capacities of
$600 \mathrm{mAh} \cdot \mathrm{g}^{-1}$ and size dependant rate capabilities (Figure 8i). In another study, Zhao et al. fabricated $\mathrm{Fe}_{3} \mathrm{O}_{4}$ nanoparticle-graphitic carbon hybrid nanosheets (Figure $8 \mathrm{j}, 8 \mathrm{k}$ ) ${ }^{[151]}$ Benefiting from the outstanding structural and electrical integrity, the $\mathrm{Fe}_{3} \mathrm{O}_{4}$-graphitic carbon hybrid demonstrated excellent rate capability and cycling performance. Even at an ultrahigh current density of $20 \mathrm{~A} \cdot \mathrm{g}^{-1}$, a capacity of $311 \mathrm{mAh} \cdot \mathrm{g}^{-1}$ could be obtained (Figure 81).

\section{$\mathrm{Fe}_{3} \mathrm{O}_{4}$-based 3D nanostructures}

Due to their multiple structural merits, $\mathrm{Fe}_{3} \mathrm{O}_{4}$-based hollow structures, such as hollow spheres and hollow cubes, have demonstrated promising lithium storage performances. ${ }^{[153-161]}$ As a typical example, Lou et al. prepared uniform $\mathrm{Fe}_{3} \mathrm{O}_{4}$ hierarchical hollow spheres comprised of nanoplate building blocks (Figures $9 \mathrm{a}$ and $9 \mathrm{~b}$ ) by an ethylene glycol-mediated solvothermal method. ${ }^{[159]}$ The product delivered a reversible capacity of $640 \mathrm{mAh} \cdot \mathrm{g}^{-1}$ at $200 \mathrm{~mA} \cdot \mathrm{g}^{-1}$, retaining $580 \mathrm{mAh} \cdot \mathrm{g}^{-1}$ after 100 cycles (Figure 9c). In another study, the same group synthesized monodisperse $\mathrm{Fe}_{3} \mathrm{O}_{4}$ hollow spheres organized by ultrathin nanosheets (Figures $9 \mathrm{~d}$ and $9 \mathrm{e}$ ), which demonstrated a high reversible capacity of $1046 \mathrm{mAh} \cdot \mathrm{g}^{-1}$ without noticeable capacity fading over 100 cycles. ${ }^{[160]}$ Such unique structures also led to remarkable rate capability, showing capacities of $992,853,716$, and $548 \mathrm{mAh} \cdot \mathrm{g}^{-1}$ at $1,2,4$, and $8 \mathrm{~A} \cdot \mathrm{g}^{-1}$, respectively (Figure 9f)
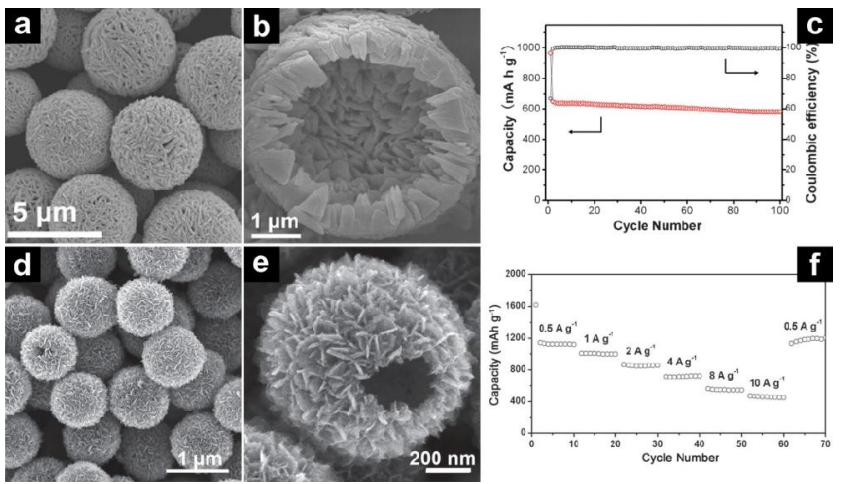

Figure 9 SEM images (a, b) and cycling performance (c) of $\mathrm{Fe}_{3} \mathrm{O}_{4}$ hierarchical hollow spheres comprised of nanoplates $;{ }^{[159]} \mathrm{SEM}$ images (d, e) and rate performance (f) of $\mathrm{Fe}_{3} \mathrm{O}_{4}$ hierarchical hollow spheres constructed by ultrathin nanosheets. ${ }^{[160]}$

With desirable free spaces for volume change accommodation, yolk@shell structures have also been fabricated to boost the electrochemical performances of $\mathrm{Fe}_{3} \mathrm{O}_{4} \cdot{ }^{[162-166]}$ Guan et al. constructed $\mathrm{Fe}_{3} \mathrm{O}_{4} @ \mathrm{C}$ yolk@shell spheres (Figure 10a) showing a specific capacity of $680 \mathrm{mAh} \cdot \mathrm{g}^{-1}$ at $5 \mathrm{~A} \cdot \mathrm{g}^{-1} \cdot{ }^{[162]}$ Paik et al. reported the synthesis of $\mathrm{Fe}_{3} \mathrm{O}_{4} @ \mathrm{C}$ yolk-shell microcubes (Figure 10b) via an "etching-in-a-box" strategy. ${ }^{[165]} \mathrm{The} \mathrm{Fe}_{3} \mathrm{O}_{4} @ \mathrm{C}$ yolk-shell boxes with an optimized etching time of $2 \mathrm{~h}$ demonstrated the best anode performance in terms of specific capacity, cycling stability, and rate capability. Guo et al. designed a novel yolk@shell structure with a $\mathrm{Fe}_{3} \mathrm{O}_{4} @ \mathrm{Fe}_{3} \mathrm{C}$ core@shell yolk and a carbon nanospindle shell (Figure 10c). ${ }^{[164]}$ This intricate yolk@shell structure demonstrated significantly enhanced electrochemical performances when compared to bare $\mathrm{Fe}_{3} \mathrm{O}_{4}$ and $\mathrm{Fe}_{3} \mathrm{O}_{4} @ \mathrm{C}$ core-shell structures. To study the effects of void size on the electrochemical performances, Yu, Zhou, and co-workers prepared a series of $\mathrm{FeO}_{x} @ \mathrm{C}$ yolk@shell structures $\left(\mathrm{Fe}_{3} \mathrm{O}_{4}\right.$ as the dominant phase) with tailored void space (Figure 10d). ${ }^{[163]}$ Only with an optimized void size, the $\mathrm{FeO}_{x} @ \mathrm{C}$ yolk@shell structures demonstrated the best cycling performance (Figure 10e). 

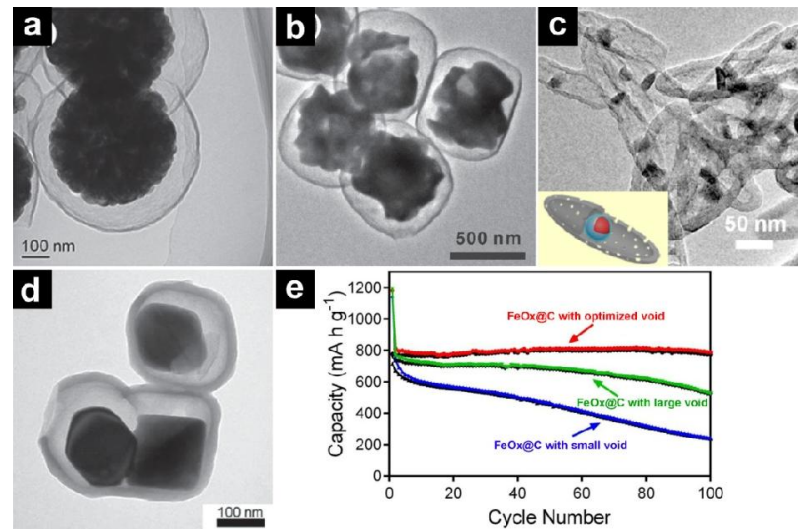

Figure 10 TEM image of $\mathrm{Fe}_{3} \mathrm{O}_{4} @ \mathrm{C}$ yolk@shell spheres (a): ${ }^{[162]}$ TEM image of $\mathrm{Fe}_{3} \mathrm{O}_{4} @ \mathrm{C}$ yolk-shell microboxes (b) ${ }^{[165]}$ TEM image of yolk@shell structures with $\mathrm{Fe}_{3} \mathrm{O}_{4} @ \mathrm{Fe}_{3} \mathrm{C}$ yolks and carbon nanospindle shells (c) ${ }^{[164]}$ TEM image (d) and cycling performance (e) of $\mathrm{FeO}_{x} @ \mathrm{C}$ yolk-shell structures with an optimized void size. ${ }^{[163]}$

$\mathrm{Fe}_{3} \mathrm{O}_{4}$-based hierarchical structures also demonstrate high lithium storage performances. Long, Ling, and co-workers reported the preparation of $\mathrm{Fe}_{3} \mathrm{O}_{4}-\mathrm{C}$ micro-flowers constructed by nanoflakes

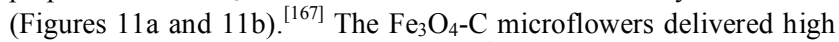
specific capacities of $920-1030 \mathrm{mAh} \cdot \mathrm{g}^{-1}$ for 150 cycles. Hyeon et al. reported a bottom-up self-assembly approach for the fabrication of $\mathrm{Fe}_{3} \mathrm{O}_{4}-\mathrm{C}$ hierarchical spheres comprised of nanoparticles (11-12 nm). ${ }^{[168]}$ Compared to random $\mathrm{Fe}_{3} \mathrm{O}_{4}$ nanoparticle aggregates, the assembled hierarchical spheres demonstrated better cyclability and higher Coulombic efficiency.

Porous carbon materials is considered as an ideal host material to encapsulate electrochemically active $\mathrm{Fe}_{3} \mathrm{O}_{4}$ for lithium storage. ${ }^{[169-177]}$ By coating $\alpha-\mathrm{Fe}_{2} \mathrm{O}_{3}$ nanospindles with glucose-derived carbon-rich polysaccharide followed by carbothermal reduction, carbon coated $\mathrm{Fe}_{3} \mathrm{O}_{4}$ nanospindles $\left(\mathrm{Fe}_{3} \mathrm{O}_{4} @ \mathrm{C}\right)$ were prepared by Wan, Guo, and co-workers (Figure 11c) ${ }^{[169]}$ By chemical vapor deposition of acetylene on $\alpha-\mathrm{Fe}_{2} \mathrm{O}_{3}$ nanorings, Zhu et al. obtained $\mathrm{Fe}_{3} \mathrm{O}_{4} @ \mathrm{C}$ nanorings (Figure 11d); during the CVD, carbon deposition and $\alpha-\mathrm{Fe}_{2} \mathrm{O}_{3}$ reduction occurred simultaneously. ${ }^{[174]}$ Through a hydrothermal method followed by carbonization, Xue et al. prepared mesoporous carbon sphere encapsulated $\mathrm{Fe}_{3} \mathrm{O}_{4}$ nanoparticles (Figure 11e). ${ }^{[176]}$ By impregnating $\mathrm{Fe}\left(\mathrm{NO}_{3}\right)_{3}$ into mesoporous carbon via a "host-guest" approach, Lee, Kim, and co-workers synthesized mesocellular carbon foam encapsulated $\mathrm{Fe}_{3} \mathrm{O}_{4}$ nanocrystals (Figure 11f). ${ }^{[170]}$ All these $\mathrm{Fe}_{3} \mathrm{O}_{4}$-porous carbon nanocomposites demonstrated superior electrochemical lithium storage performances. Especially, the $\mathrm{Fe}_{3} \mathrm{O}_{4}$ nanoparticle embedded in mesoporous carbon spheres exhibited stable capacities for 290 cycles at various current densities ranging from $0.5-10 \mathrm{~A} \cdot \mathrm{g}^{-1} \cdot{ }^{[176]}$

\section{Conclusions}

This review provides a comprehensive summary on the nanostructure engineering of iron oxides $\left(\mathrm{Fe}_{2} \mathrm{O}_{3}, \mathrm{Fe}_{3} \mathrm{O}_{4}\right.$ and $\left.\gamma-\mathrm{Fe}_{2} \mathrm{O}_{3}\right)$ for high-capacity lithium storage. Various iron oxide nanostructures, including 0D nanoparticles, 1D nanowires/nanorods/nanofibers/nanotubes, 2D nanoflakes/nanosheets, as well as 3D porous/hollow/hierarchical architectures, have been constructed for lithium storage. These delicate nanostructures show not only reduced ion/electron diffusion lengths but also sufficient free space for volume change accommodation and strain relaxation, leading to enhanced cycling stability and rate capability. Moreover, the combination of nanostructured iron oxide with conductive carbon integrates the advantages of both components, further boosting the structural stability and electrochemical performances.

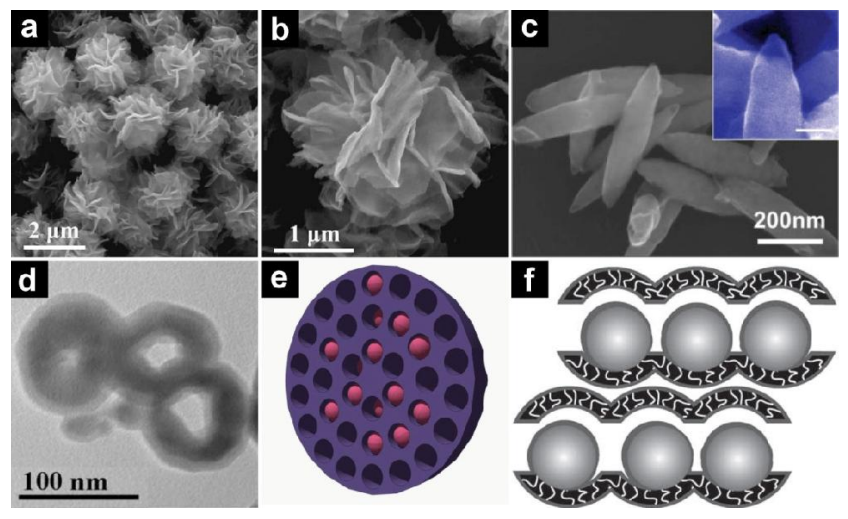

Figure 11 SEM images of $\mathrm{Fe}_{3} \mathrm{O}_{4}-\mathrm{C}$ micro-flowers (a, b); ${ }^{[167]} \mathrm{SEM}$ image of carbon coated $\mathrm{Fe}_{3} \mathrm{O}_{4}$ nanospindles (c); ${ }^{[169]}$ TEM image of carbon coated $\mathrm{Fe}_{3} \mathrm{O}_{4}$ nanorings (d); ${ }^{[174]}$ schematic illustration of mesoporous carbon sphere encapsulated $\mathrm{Fe}_{3} \mathrm{O}_{4}$ nanoparticles (e); ${ }^{[176]}$ schematic illustration of mesocellular carbon foam encapsulated $\mathrm{Fe}_{3} \mathrm{O}_{4}$ nanocrystals (f). ${ }^{[170]}$

Despite the design of iron oxide nanostructures and the hybridization of iron oxide with conductive carbon could address the volume change issue and improve the cyclability effectively, some other issues still remain for iron oxide based anode materials. These issues include: (1) the low initial Coulombic efficiency of iron oxide base anode materials, (2) the relatively high charge plateau of iron oxide, and (3) the large voltage hysteresis between charge and discharge. Before the practical application of iron oxides in LIBs, these issues should be overcome. With the further development of nanostructure engineering, it is believed that the iron oxides would play a significant role in next-generation LIBs as high-performance anode materials.

\section{Acknowledgement}

This work was supported by the National Key Research and Development Program of China (2016YFA0202603), the National Basic Research Program of China (2013CB934103), the Programme of Introducing Talents of Discipline to Universities (B17034), the National Natural Science Foundation of China (51521001, 51602239, 21673171, 51502226), the National Natural Science Fund for Distinguished Young Scholars (51425204), the Hubei Provincial Natural Science Foundation of China (2016CFB267), and the Fundamental Research Funds for the Central Universities (WUT: 2016III001, 2016III002, 2016III003, 2016IVA090, 2017III009, 2017III008, 2017III007).

\section{References}

[1] Tarascon, J. M.; Armand, M. Nature 2001, 414, 359.

[2] Armand, M.; Tarascon, J. M. Nature 2008, 451, 652.

[3] Dunn, B.; Kamath, H.; Tarascon, J.-M. Science 2011, 334, 928.

[4] Cabana, J.; Monconduit, L.; Larcher, D.; Palacín, M. R. Adv. Mater. 2010, 22, E170.

[5] Wu, H.; Cui, Y. Nano Today 2012, 7, 414.

[6] Zhu, G.-N.; Wang, Y.-G.; Xia, Y.-Y. Energy Environ. Sci. 2012, 5, 6652.

[7] Chen, Z.; Belharouak, I.; Sun, Y. K.; Amine, K. Adv. Funct. Mater. 2013, 23, 959.

[8] Dylla, A. G.; Henkelman, G.; Stevenson, K. J. Acc. Chem. Res. 2013, 46, 1104.

[9] Reddy, M. V.; Subba Rao, G. V.; Chowdari, B. V. R. Chem. Rev. 2013, $113,5364$.

[10] Xu, W.; Wang, J.; Ding, F.; Chen, X.; Nasybulin, E.; Zhang, Y.; Zhang, 
J.-G. Energy Environ. Sci. 2014, 7, 513.

[11] Zhao, Y.; Li, X.; Yan, B.; Xiong, D.; Li, D.; Lawes, S.; Sun, X. Adv. Energy Mater. 2016, 6, 1502175.

[12] Yu, S.-H.; Lee, S. H.; Lee, D. J.; Sung, Y.-E.; Hyeon, T. Small 2016, 12, 2146.

[13] Lin, D.; Liu, Y.; Cui, Y. Nat. Nanotechnol. 2017, 12, 194.

[14] Guo, Y.; Li, H.; Zhai, T. Adv. Mater. 2017, 29, 1700007.

[15] Xin, S.; You, Y.; Wang, S.; Gao, H.-C.; Yin, Y.-X.; Guo, Y.-G. ACS Appl. Mater. Interfaces 2017, 2, 1385.

[16] Zhao, Y.; Wang, L. P.; Sougrati, M. T.; Feng, Z.; Leconte, Y.; Fisher, A.; Srinivasan, M.; Xu, Z. Adv. Energy Mater. 2017, 7, 1601424.

[17] Poizot, P.; Laruelle, S.; Grugeon, S.; Dupont, L.; Tarascon, J. M. Nature 2000, 407, 496 .

[18] Zhang, L.; Wu, H. B.; Lou, X. W. Adv. Energy Mater. 2014, 4, 1300958.

[19] Zhou, W.; Guo, L. Chem. Soc. Rev. 2015, 44, 6697.

[20] Lin, Y.-M.; Abel, P. R.; Heller, A.; Mullins, C. B. J. Phys. Chem. Lett. 2011, 2, 2885.

[21] Bruce, P. G.; Scrosati, B.; Tarascon, J.-M. Angew. Chem., Int. Ed. 2008, 47, 2930.

[22] Guo, Y.-G.; Hu, J.-S.; Wan, L.-J. Adv. Mater. 2008, 20, 2878.

[23] Sun, Y.; Liu, N.; Cui, Y. Nat. Energy 2016, 1, 16071.

[24] Sivula, K.; Le Formal, F.; Grätzel, M. ChemSusChem 2011, 4, 432.

[25] Mai, L.; Tian, X.; Xu, X.; Chang, L.; Xu, L. Chem. Rev. 2014, 114, 11828.

[26] Wu, C.; Yin, P.; Zhu, X.; OuYang, C.; Xie, Y. J. Phys. Chem. B 2006, 110, 17806.

[27] Zeng, S.; Tang, K.; Li, T. J. Colloid Interfaces Sci. 2007, 312, 513.

[28] Liu, H.; Wang, G.; Park, J.; Wang, J.; Liu, H.; Zhang, C. Electrochim. Acta 2009, 54, 1733.

[29] Liu, H.; Wexler, D.; Wang, G. J. Alloys Compd. 2009, 487, L24.

[30] Song, Y.; Qin, S.; Zhang, Y.; Gao, W.; Liu, J. J. Phys. Chem. C 2010, 114 , 21158.

[31] Yao, X.; Tang, C.; Yuan, G.; Cui, P.; Xu, X.; Liu, Z. Electrochem. Commun. 2011, 13, 1439.

[32] Tartaj, P.; Amarilla, J. M. J. Power Sources 2011, 196, 2164.

[33] Zhao, K.; Wen, M.; Dong, Y.; Zhang, L.; Yan, M.; Xu, W.; Niu, C.; Zhou, L.; Wei, Q.; Ren, W.; Wang, X.; Mai, L. Adv. Energy Mater. 2017, 7, 1601582.

[34] Chen, J.; Xu, L.; Li, W.; Gou, X. Adv. Mater. 2005, 17, 582.

[35] Wang, Z.; Luan, D.; Madhavi, S.; Li, C. M.; Lou, X. W. Chem. Commun. 2011, 47, 8061 .

[36] Liu, J.; Li, Y.; Fan, H.; Zhu, Z.; Jiang, J.; Ding, R.; Hu, Y.; Huang, X. Chem. Mater. 2010, 22, 212

[37] Chaudhari, S.; Srinivasan, M. J. Mater. Chem. 2012, 22, 23049.

[38] Zeng, W.; Zheng, F.; Li, R.; Zhan, Y.; Li, Y.; Liu, J. Nanoscale 2012, 4, 2760 .

[39] Ji, L.; Toprakci, O.; Alcoutlabi, M.; Yao, Y.; Li, Y.; Zhang, S.; Guo, B.; Lin, Z.; Zhang, X. ACS Appl. Mater. Interfaces 2012, 4, 2672.

[40] Zhang, X.; Liu, H.; Petnikota, S.; Ramakrishna, S.; Fan, H. J. J. Mater. Chem. A 2014, 2, 10835.

[41] Cho, J. S.; Hong, Y. J.; Kang, Y. C. ACS Nano 2015, 9, 4026.

[42] Yu, W.-J.; Hou, P.-X.; Zhang, L.-L.; Li, F.; Liu, C.; Cheng, H.-M. Chem. Commun. 2010, 46, 8576.

[43] Zhou, G.; Wang, D.-W.; Hou, P.-X.; Li, W.; Li, N.; Liu, C.; Li, F.; Cheng, H.-M. J. Mater. Chem. 2012, 22, 17942.

[44] Yu, W.-J.; Hou, P.-X.; Li, F.; Liu, C. J. Mater. Chem. 2012, 22, 13756.

[45] Zhao, Y.; Li, J.; Ding, Y.; Guan, L. Chem. Commun. 2011, 47, 7416.

[46] Reddy, M. V.; Yu, T.; Sow, C. H.; Shen, Z. X.; Lim, C. T.; Rao, G. V. S.; Chowdari, B. V. R. Adv. Funct. Mater. 2007, 17, 2792.

[47] Li, L.; Wu, H. B.; Yu, L.; Madhavi, S.; Lou, X. W. Adv. Mater. Interfaces 2014, $1,1400050$.

[48] Lu, J.; Peng, Q.; Wang, Z.; Nan, C.; Li, L.; Li, Y. J. Mater. Chem. A 2013, 1,5232 .

[49] Zhu, X.; Zhu, Y.; Murali, S.; Stoller, M. D.; Ruoff, R. S. ACS Nano 2011, $5,3333$.

[50] Zou, Y.; Kan, J.; Wang, Y. J. Phys. Chem. C 2011, 115, 20747.

[51] Wang, G.; Liu, T.; Luo, Y.; Zhao, Y.; Ren, Z.; Bai, J.; Wang, H. J. Alloys
Compd. 2011, 509, L216.

[52] Xue, X.-Y.; Ma, C.-H.; Cui, C.-X.; Xing, L.-L. Solid State Sci. 2011, 13, 1526.

[53] Zhang, M.; Qu, B.; Lei, D.; Chen, Y.; Yu, X.; Chen, L.; Li, Q.; Wang, Y.; Wang, T. J. Mater. Chem. 2012, 22, 3868.

[54] Xiao, L.; Wu, D.; Han, S.; Huang, Y.; Li, S.; He, M.; Zhang, F.; Feng, X. ACS App. Mater. Interfaces 2013, 5, 3764.

[55] Qu, J.; Yin, Y.-X.; Wang, Y.-Q.; Yan, Y.; Guo, Y.-G.; Song, W.-G. $A C S$ Appl. Mater. Interfaces 2013, 5, 3932.

[56] Su, Q.; Xie, D.; Zhang, J.; Du, G.; Xu, B. ACS Nano 2013, 7, 9115.

[57] Chen, S.; Bao, P.; Wang, G. Nano Energy 2013, 2, 425.

[58] Zhou, G.-W.; Wang, J.; Gao, P.; Yang, X.; He, Y.-S.; Liao, X.-Z.; Yang, J.; Ma, Z.-F. Ind. Eng. Chem. Res. 2013, 52, 1197.

[59] Li, L.; Zhou, G.; Weng, Z.; Shan, X.-Y.; Li, F.; Cheng, H.-M. Carbon 2014, 67, 500 .

[60] Zhang, H.; Zhou, L.; Yu, C. RSC Adv. 2014, 4, 495.

[61] Chen, J. S.; Zhu, T.; Yang, X. H.; Yang, H. G.; Lou, X. W. J. Am. Chem. Soc. 2010, 132, 13162.

[62] Lou, X. W.; Archer, L. A.; Yang, Z. Adv. Mater. 2008, 20, 3987.

[63] Zhou, L.; Zhao, D.; Lou, X. W. Adv. Mater. 2012, 24, 745.

[64] Zhou, L.; Zhuang, Z.; Zhao, H.; Lin, M.; Zhao, D.; Mai, L. Adv. Mater 2017, 29, 1602914.

[65] Lai, X.; Halpert, J. E.; Wang, D. Energy Environ. Sci. 2012, 5, 5604.

[66] Qi, J.; Lai, X.; Wang, J.; Tang, H.; Ren, H.; Yang, Y.; Jin, Q.; Zhang, L.; Yu, R.; Ma, G.; Su, Z.; Zhao, H.; Wang, D. Chem. Soc. Rev. 2015, 44, 6749.

[67] Zeng, S.; Tang, K.; Li, T.; Liang, Z.; Wang, D.; Wang, Y.; Zhou, W. J. Phys. Chem. C 2007, 111, 10217.

[68] Wu, Z.; Yu, K.; Zhang, S.; Xie, Y. J. Phys. Chem. C 2008, 112, 11307.

[69] Zhou, J.; Song, H.; Chen, X.; Zhi, L.; Yang, S.; Huo, J.; Yang, W. Chem. Mater. 2009, 21, 2935.

[70] Wang, B.; Chen, J. S.; Wu, H. B.; Wang, Z.; Lou, X. W. J. Am. Chem. Soc. 2011, 133, 17146.

[71] Wang, B.; Chen, J. S.; Lou, X. W. J. Mater. Chem. 2012, 22, 9466.

[72] Zhu, J.; Yin, Z.; Yang, D.; Sun, T.; Yu, H.; Hoster, H. E.; Hng, H. H.; Zhang, H.; Yan, Q. Energy Environ. Sci. 2013, 6, 987.

[73] Jeong, J.-M.; Choi, B. G.; Lee, S. C.; Lee, K. G.; Chang, S.-J.; Han, Y.-K.; Lee, Y. B.; Lee, H. U.; Kwon, S.; Lee, G.; Lee, C.-S.; Huh, Y. S. Adv. Mater. 2013, 25, 6250.

[74] Zhou, L.; Xu, H.; Zhang, H.; Yang, J.; B. Hartono, S.; Qian, K.; Zou, J.; Yu, C. Chem. Commun. 2013, 49, 8695.

[75] Padashbarmchi, Z.; Hamidian, A. H.; Zhang, H.; Zhou, L.; Khorasani, N.; Kazemzad, M.; Yu, C. RSC Adv. 2015, 5, 10304.

[76] Xu, S.; Hessel, C. M.; Ren, H.; Yu, R.; Jin, Q.; Yang, M.; Zhao, H.; Wang, D. Energy Environ. Sci. 2014, 7, 632.

[77] Son, M. Y.; Hong, Y. J.; Lee, J.-K.; Kang, Y. C. Nanoscale 2013, 5, 11592.

[78] Brezesinski, K.; Haetge, J.; Wang, J.; Mascotto, S.; Reitz, C.; Rein, A.; Tolbert, S. H.; Perlich, J.; Dunn, B.; Brezesinski, T. Small 2011, 7, 407.

[79] Xu, X.; Cao, R.; Jeong, S.; Cho, J. Nano Lett. 2012, 12, 4988.

[80] Xu, Y.; Jian, G.; Liu, Y.; Zhu, Y.; Zachariah, M. R.; Wang C. Nano Energy 2014, 3, 26.

[81] Cao, K.; Jiao, L.; Liu, H.; Liu, Y.; Wang, Y.; Guo, Z.; Yuan, H. Adv Energy Mater. 2015, 5, 1401421.

[82] Zhang, H.; Sun, X.; Huang, X.; Zhou, L. Nanoscale 2015, 7, 3270.

[83] Gao, G.; Yu, L.; Wu, H. B.; Lou, X. W. Small 2014, 10, 1741.

[84] Wang, Z.; Luan, D.; Madhavi, S.; Hu, Y.; Lou, X. W. Energy Environ. Sci. 2012, 5, 5252 .

[85] Wang, Y.; Xu, J.; Wu, H.; Xu, M.; Peng, Z.; Zheng, G. J. Mater. Chem. 2012, 22, 21923.

[86] Luo, J.; Xia, X.; Luo, Y.; Guan, C.; Liu, J.; Qi, X.; Ng, C. F.; Yu, T.; Zhang, H.; Fan, H. J. Adv. Energy Mater. 2013, 3, 737.

[87] Xia, H.; Xiong, W.; Lim, C. K.; Yao, Q.; Wang, Y.; Xie, J. Nano Res. 2014, 7, 1797.

[88] Zhou, W.; Cheng, C.; Liu, J.; Tay, Y. Y.; Jiang, J.; Jia, X.; Zhang, J.; Gong, H.; Hng, H. H.; Yu, T.; Fan, H. J. Adv. Funct. Mater. 2011, 21, 2439.

[89] Gu, X.; Chen, L.; Ju, Z.; Xu, H.; Yang, J.; Qian, Y. Adv. Funct. Mater. 
2013, 23, 4049 .

[90] Kang, N.; Park, J. H.; Choi, J.; Jin, J.; Chun, J.; Jung, I. G.; Jeong, J.; Park, J.-G.; Lee, S. M.; Kim, H. J.; Son, S. U. Angew. Chem., Int. Ed. 2012, 51, 6626

[91] Yu, W.-J.; Zhang, L.; Hou, P.-X.; Li, F.; Liu, C.; Cheng, H.-M. Adv. Energy Mater. 2016, 6, 1501755.

[92] Wu, Y.; Zhu, P.; Reddy, M. V.; Chowdari, B. V. R.; Ramakrishna, S. ACS Appl. Mater. Interfaces 2014, 6, 1951.

[93] Wu, P.; Xie, K.; Xu, X.; Li, J.; Tang, Y.; Zhou, Y.; Lu, T. Mater. Res. Bull. 2015, 64, 106.

[94] Sun, Y. F.; Zhang, J. J.; Huang, T.; Liu, Z. L.; Yu, A. S. Int. J. Electrochem. Sci. 2013, 8, 2918.

[95] Ma, Y.; Ji, G.; Lee, J. Y. J. Mater. Chem. 2011, 21, 13009.

[96] Vargas, O.; Caballero, Á.; Morales, J. Electrochim. Acta 2014, 130, 551.

[97] Kim, I. T.; Magasinski, A.; Jacob, K.; Yushin, G.; Tannenbaum, R. Carbon 2013, 52, 56.

[98] Tian, L.-L.; Zhang, M.-J.; Wu, C.; Wei, Y.; Zheng, J.-X.; Lin, L.-P.; Lu, J.; Amine, K.; Zhuang, Q.-C.; Pan, F. ACS Appl. Mater. Interfaces 2015, 7, 26284.

[99] Xu, J.-S.; Zhu, Y.-J. ACS Appl. Mater. Interfaces 2012, 4, 4752.

[100] Liang, J.; Xiao, C. H.; Chen, X.; Gao, R. X.; Ding, S. J. Nanotechnology 2016, 27, 215403.

[101] Koo, B.; Xiong, H.; Slater, M. D.; Prakapenka, V. B.; Balasubramanian, M.; Podsiadlo, P.; Johnson, C. S.; Rajh, T.; Shevchenko, E. V. Nano Lett. 2012, 12, 2429.

[102] Zhang, L.; Wu, H. B.; Madhavi, S.; Hng, H. H.; Lou, X. W. J. Am. Chem. Soc. 2012, 134, 17388.

[103] Zhang, L.; Wu, H.B .; Lou, X. W. J. Am. Chem. Soc. 2013, 135, 10664.

[104] Hu, J.; Zheng, J.; Tian, L.; Duan, Y.; Lin, L.; Cui, S.; Peng, H.; Liu, T.; Guo, H.; Wang, X.; Pan, F. Chem. Commun. 2015, 51, 7855.

[105] Han, F.; Li, D.; Li, W.-C.; Lei, C.; Sun, Q.; Lu, A.-H. Adv. Funct. Mater. 2013, 23, 1692.

[106] Li, Z.; Li, B.; Yin, L.; Qi, Y. ACS Appl. Mater. Interfaces 2014, 6, 8098.

[107] Taberna, L.; Mitra, S.; Poizot, P.; Simon, P.; Tarascon, J. M. Nat. Mater. 2006, $5,567$.

[108] Cui, Z.-M.; Jiang, L.-Y.; Song, W.-G.; Guo, Y.-G. Chem. Mater. 2009, 21, 1162.

[109] Chen, J. S.; Zhang, Y.; Lou, X. W. ACS Appl. Mater. Interfaces 2011, 3, 3276 .

[110] Zhao, N.; Wu, S.; He, C.; Wang, Z.; Shi, C.; Liu, E.; Li, J. Carbon 2013, 57,130 .

[111] Lei, C.; Han, F.; Li, D.; Li, W.-C.; Sun, Q.; Zhang, X.-Q.; Lu, A.-H. Nanoscale 2013, 5, 1168.

[112] Li, L.; Wang, T.; Zhang, L.; Su, Z.; Wang, C.; Wang, R. Chem. Eur. J. 2012, 18, 11417.

[113] Wang, Y.; Zhang, L.; Gao, X.; Mao, L.; Hu, Y.; Lou, X. W. Small 2014, 10,2815 .

[114] Liu, H.; Wang, G.; Wang, J.; Wexler, D. Electrochem. Commun. 2008, 10, 1879.

[115] Muraliganth, T.; Murugan, A. V.; Manthiram, A. Chem. Commun. 2009, 47, 7360

[116] Yuan, S. M.; Li, J. X.; Yang, L. T.; Su, L. W.; Liu, L.; Zhou, Z. ACS Appl. Mater. Interfaces 2011, 3, 705.

[117] Zhu, T.; Chen, J. S.; Lou, X. W. J. Phys. Chem. C 2011, 115, 9814.

[118] Xiong, Q. Q.; Lu, Y.; Wang, X. L.; Gu, C. D.; Qiao, Y. Q.; Tu, J. P. J. Alloys Compd. 2012, 536, 219.

[119] Xiao, Z.; Xia, Y.; Ren, Z.; Liu, Z.; Xu, G.; Chao, C.; Li, X.; Shen, G.; Han, G. J. Mater. Chem. 2012, 22, 20566.

[120] Lang, L.; Xu, Z. ACS Appl. Mater. Interfaces 2013, 5, 1698.

[121] Li, L.; Kovalchuk, A.; Fei, H.; Peng, Z.; Li, Y.; Kim, N. D.; Xiang, C.; Yang, Y.; Ruan, G.; Tour, J. M. Adv. Energy Mater. 2015, 5, 1500171.

[122] Wang, L.; Yu, Y.; Chen, P. C.; Zhang, D. W.; Chen, C. H. J. Power Sources 2008, 183, 717.

[123] Luo, H.; Huang, K.; Sun, B.; Zhong, J. Electrochim. Acta 2014, 149, 11.

[124] Im, M. E.; Pham-Cong, D.; Kim, J. Y.; Choi, H. S.; Kim. J. H.; Kim, J. P.; Kim, J.; Jeong, S. Y.; Cho, C. R. J. Power Sources 2015, 284, 392.
[125] Wang, H.; Wang, G.; Yuan, S.; Ma, D.; Li, Y.; Zhang, Y. Nano Res. 2015, $8,1659$.

[126] Xie, W.; Li, S.; Wang, S.; Xue, S.; Liu, Z.; Jiang, X.; He, D. ACS Appl. Mater. Interfaces 2014, 6, 20334.

[127] Ban, C.; Wu, Z.; Gillaspie, D. T.; Chen, L.; Yan, Y.; Blackburn, J. L.; Dillon, A. C. Adv. Mater. 2010, 22, E145.

[128] Wu, Y.; Wei, Y.; Wang, J.; Jiang, K.; Fan, S. Nano Lett. 2013, 13, 818.

[129] Ren, S.; Prakash, R.; Wang, D.; Chakravadhanula, V. S. K.; Fichtner, M. ChemSusChem 2012, 5,1397.

[130] Cheng, J.; Wang, B.; Park, C.-M.; Wu, Y.; Huang, H.; Nie, F. Chem. Eur. J. 2013, 19, 9866 .

[131] Yang, L.; Hu, J.; Dong, A.; Yang, D. Electrochim. Acta 2014, 144, 235.

[132] Li, S.; Wang, M.; Luo, Y.; Huang, J. ACS Appl. Mater. Interfaces 2016, 8, 17343.

[133] Wan, Y.; Yang Z.; Xiong G.; Guo R.; Liu Z.; Luo H. J. Power Sources 2015, 294, 414.

[134] Saadat, S.; Zhu, J.; Sim, D. H.; Hng, H. H.; Yazami, R.; Yan, Q. J. Mater. Chem. A 2013, 1, 8672.

[135] Han, F.; Ma, L.; Sun, Q.; Lei, C.; Lu, A. Nano Res. 2014, 7, 1706.

[136] An, Q.; Lv, F.; Liu, Q.; Han, C.; Zhao, K.; Sheng, J.; Wei, Q.; Yan, M.; Mai, L. Nano Lett. 2014, 14, 6250.

[137] Zhou, G.; Wang, D.-W.; Li, F.; Zhang, L.; Li, N.; Wu, Z.-S.; Wen, L.; Lu, G. Q.; Cheng, H.-M. Chem. Mater. 2010, 22, 5306.

[138] Lian, P.; Zhu, X.; Xiang, H.; Li, Z.; Yang, W.; Wang, H. Electrochim. Acta 2010, 56, 834.

[139] Su, J.; Cao, M.; Ren, L.; Hu, C. J. Phys. Chem. C 2011, 115, 14469.

[140] Li, X.; Huang, X.; Liu, D.; Wang, X.; Song, S.; Zhou, L.; Zhang, H. J. Phys. Chem. C 2011, 115, 21567.

[141] Ji, L.; Tan, Z.; Kuykendall, T. R.; Aloni, S.; Xun, S.; Lin, E.; Battaglia, V.; Zhang, Y. Phys. Chem. Chem. Phys. 2011, 13, 7170.

[142] Zhou, J.; Song, H.; Ma, L.; Chen, X. RSC Adv. 2011, 1, 782.

[143] Wang, J.-Z.; Zhong, C.; Wexler, D.; Idris, N. H.; Wang, Z.-X.; Chen, L.-Q.; Liu, H.-K. Chem. Eur. J. 2011, 17, 661.

[144] Wei, W.; Yang, S.; Zhou, H.; Lieberwirth, I.; Feng, X.; Müllen, K. Adv. Mater. 2013, 25, 2909.

[145] Luo, J.; Liu, J.; Zeng, Z.; Ng, C. F.; Ma, L.; Zhang, H.; Lin, J.; Shen, Z.; Fan, H. J. Nano Lett. 2013, 13, 6136.

[146] Wang, R.; Xu, C.; Sun, J.; Gao, L.; Lin, C. J. Mater. Chem. A 2013, 1, 1794.

[147] Zhao, L.; Gao, M.; Yue, W.; Jiang, Y.; Wang, Y.; Ren, Y.; Hu, F. ACS Appl. Mater. Interfaces 2015, 7, 9709.

[148] Pan, L.; Zhu, X.-D.; Xie, X.-M.; Liu, Y.-T. Adv. Funct. Mater. 2015, 25, 3341.

[149] Fan, L.; Li, B.; Rooney, D. W.; Zhang, N.; Sun, K. Chem. Commun. 2015, $51,1597$.

[150] Jang, B.; Park, M.; Chae, O. B.; Park, S.; Kim, Y.; Oh, S. M.; Piao, Y.; Hyeon, T. J. Am. Chem. Soc. 2012, 134, 15010.

[151] He, C.; Wu, S.; Zhao, N.; Shi, C.; Liu, E.; Li, J. ACS Nano 2013, 7, 4459.

[152] Wu, S.; Wang, Z.; He, C.; Zhao, N.; Shi, C.; Liu, E.; Li, J. J. Mater. Chem. A 2013, 1,11011 .

[153] Chen, D.; Ji, G.; Ma, Y.; Lee, J. Y.; Lu, J. ACS Appl. Mater. Interfaces 2011, 3, 3078 .

[154] Lim, H.-S.; Jung, B.-Y.; Sun, Y.-K.; Suh, K.-D. Electrochim. Acta 2012, $75,123$.

[155] Zhang, J.; Yao, Y.; Huang, T.; Yu, A. Electrochim. Acta 2012, 78, 502.

[156] Chen, Y.; Xia, H.; Lu, L.; Xue, J. J. Mater. Chem. 2012, 22, 5006.

[157] Xiong, Q. Q.; Tu, J. P.; Lu, Y.; Chen, J.; Yu, Y. X.; Qiao, Y. Q.; Wang, X. L.; Gu, C. D. J. Phys. Chem. C 2012, 116, 6495.

[158] Zhang, Q.; Shi, Z.; Deng, Y.; Zheng, J.; Liu, G.; Chen, G. J. Power Sources 2012, 197, 305.

[159] Wang, B.; Wu, H. B.; Zhang, L.; Lou, X. W. Angew. Chem., Int. Ed. 2013, 52,4165 .

[160] Ma, F.-X.; Hu, H.; Wu, H. B.; Xu, C.-Y.; Xu, Z.; Zhen, L.; Lou, X. W. Adv. Mater. 2015, 27, 4097.

[161] Liu, J.; Xu, X.; Hu, R.; Yang, L.; Zhu, M. Adv. Energy Mater. 2016, 6, 1600256 . 
[162] Zhao, Y.; Li, J.; Wu, C.; Ding, Y.; Guan, L. ChemPlusChem 2012, 77, 748 .

[163] Zhang, H.; Zhou, L.; Noonan, O.; Martin, D. J.; Whittaker, A. K.; Yu, C. Adv. Funct. Mater. 2014, 24, 4337.

[164] Zhang, J.; Wang, K.; Xu, Q.; Zhou, Y.; Cheng, F.; Guo, S. ACS Nano 2015, 9, 3369 .

[165] Liu, Z.; Yu, X.-Y.; Paik, U. Adv. Energy Mater. 2016, 6, 1502318.

[166] Yang, L.; Guo, G.; Sun, H.; Shen, X.; Hu, J.; Dong, A.; Yang, D. Electrochim. Acta 2016, 190, 797.

[167] Jin, S.; Deng, H.; Long, D.; Liu, X.; Zhan, L.; Liang, X.; Qiao, W.; Ling, L. J. Power Sources 2011, 196, 3887.

[168] Lee, S. H.; Yu, S.-H.; Lee, J. E.; Jin, A.; Lee, D. J.; Lee, N.; Jo, H.; Shin, K.; Ahn, T.-Y.; Kim, Y.-W.; Choe, H.; Sung, Y.-E.; Hyeon, T. Nano Lett. 2013, 13, 4249 .

[169] Zhang, W.-M.; Wu, X.-L.; Hu, J.-S.; Guo, Y.-G.; Wan, L.-J. Adv. Funct.
Mater. 2008, 18, 3941.

[170] Kang, E.; Jung, Y. S.; Cavanagh, A. S.; Kim, G.-H.; George, S. M.; Dillon, A. C.; Kim, J. K.; Lee, J. Adv. Funct. Mater. 2011, 21, 2430.

[171] Yoon, T.; Chae, C.; Sun, Y.-K.; Zhao, X.; Kung, H. H.; Lee, J. K. J. Mater. Chem. 2011, 21, 17325.

[172] Latorre-Sanchez, M.; Primo, A.; Garcia, H. J. Mater. Chem. 2012, 22, 21373.

[173] Banerjee, A.; Gokhale, R.; Bhatnagar, S.; Jog, J.; Bhardwaj, M.; Lefez, B.; Hannoyer, B.; Ogale, S. J.Mater. Chem. 2012, 22, 19694.

[174] Wang, L.; Liang, J.; Zhu, Y.; Mei, T.; Zhang, X.; Yang, Q.; Qian, Y. Nanoscale 2013, 5, 3627.

[175] Su, L.; Zhong, Y.; Zhou, Z. J. Mater. Chem. A 2013, 1, 15158.

[176] Chen, Y.; Song, B.; Li, M.; Lu, L.; Xue, J. Adv. Funct. Mater. 2014, 24, 319.

[177] Wang, L.; Zhuo, L.; Zhang, C.; Zhao, F. Chem. Eur. J. 2014, 20, 4308. 